$$
\begin{gathered}
\text { RECENED } \\
\text { OEC } 191994 \\
\text { OSTI }
\end{gathered}
$$

\title{
A Finite Element Analysis of
}

Room Temperature Silicon Crystals for the Advanced Photon Source Bending-Magnet and Insertion-Device Beams

by L. Assoufid, W.-K. Lee, and D.M. Mills

\section{August 1994}

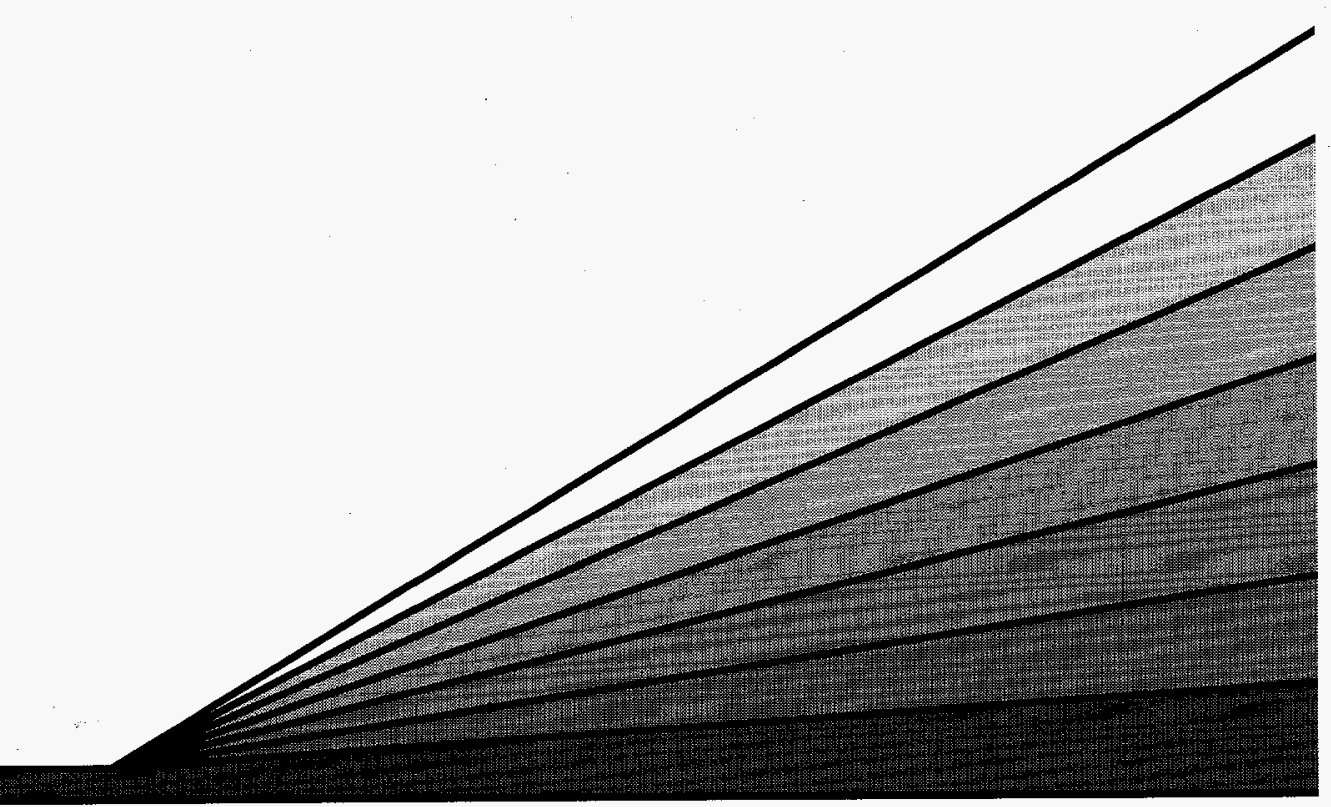

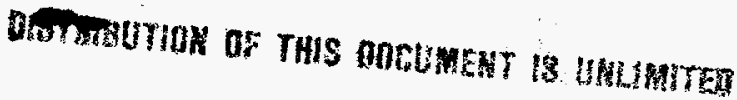


Argonne National Laboratory, with facilities in the states of Illinois and Idaho, is owned by the United States government, and operated by The University of Chicago under the provisions of a contract with the Department of Energy.

\title{
DISCLAIMER
}

This report was prepared as an account of work sponsored by an agency of the United States Government. Neither the United States Government nor any agency thereof, nor any of their employees, makes any warranty, express or implied, or assumes any legal liability or responsibility for the accuracy, completeness, or usefulness of any information, apparatus, product, or process disclosed, or represents that its use would not infringe privately owned rights. Reference herein to any specific commercial product, process, or service by trade name, trademark, manufacturer, or otherwise, does not necessarily constitute or imply its endorsement, recommendation, or favoring by the United States Government or any agency thereof. The views and opinions of authors expressed herein do not necessarily state or reflect those of the United States Government or any agency thereof.

Reproduced from the best available copy.

Available to DOE and DOE contractors from the Office of Scientific and Technical Information

\author{
P.O. Box 62
}

Oak Ridge, TN 37831

Prices available from (615) 576-8401

Available to the public from the National Technical Information Service

U.S. Department of Commerce

5285 Port Royal Road

Springfield, VA 22161 


\section{DISCLAIMER}

Portions of this document may be illegible in electronic image products. Images are produced from the best available original document. 
Distribution Category: Atomic, Molecular, and Chemical Physics (UC-411)

\title{
ARGONNE NATIONAL LABORATORY \\ 9700 South Cass Avenue \\ Argonne, Illinois 6043
}

\section{ANL/APS/TB-19}

\section{A Finite Element Analysis of Room Temperature Silicon Crystals for the Advanced Photon Source Bending-Magnet and Insertion-Device Beams}

\author{
Lahsen Assoufid, Wah-Keat Lee, and Dennis M. Mills \\ Experimental Facilities Division \\ Advanced Photon Source
}

August 1994

work sponsored by

U.S. DEPARTMENT OF ENERGY
Office of Energy Research MTIER 


\section{Contents}

I. Introduction 1

II. Parameters used for FEA Calculations 2

A. The heat transfer coefficient 2

B. Materials properties 3

III. The Bending-Magnet Monochromator 6

A. Properties of the source 6

B. Description and analyses of the crystal 7

C. Temperature and distortion results 9

D. Conclusion 10

IV. The Wiggler A Monochromator 19

A. Properties of the source 19

B. Description and analyses of the crystal 20

C. Temperature and distortion results 22

D. Conclusion 25

V. The Inclined Crystal for Undulator A 37

A. Properties of the source 37

B. Description and analyses of the crystal 38

C. Temperature and distortion results 39

D. Conclusion 40

$\begin{array}{ll}\text { VI. Experimental Results } & 50\end{array}$

VII. Acknowledgment $\quad 54$

$\begin{array}{ll}\text { VIII. References } & 54\end{array}$ 


\title{
A Finite Element Analysis of Room Temperature Silicon Crystals for the Advanced Photon Source Bending-Magnet and Insertion-Device Beams
} Lahsen Assoufid, Wah-Keat Lee, and Dennis M. Mills

\begin{abstract}
The third generation of synchrotron radiation sources, such as the Advanced Photon Source (APS), will provide users with a high brilliance $x$-ray beam with high power and power densities. In many cases, the first optical component to intercept the $x$-ray beam is a silicon-crystal monochromator. Due to extreme heat loading, the photon throughput and brilliance will be severely degraded if the monochromator is not properly designed (or cooled). This document describes a series of finite element analyses performed on room temperature silicon for the three standard APS sources, namely, the bending magnet, Wiggler A, and Undulator A. The modeling is performed with the silicon cooled directly with water or liquid gallium through rectangular channels. The temperature distributions and thermally induced deformations are presented.
\end{abstract}

\section{Introduction}

The Advanced Photon Source (APS) will provide researchers with x-ray beams of unparalleled brilliance. Concomitant with this increase in brilliance is a substantial increase in the total power and power density compared to those from existing sources. The APS has put considerable effort into exploring various approaches to mitigate the thermal distortion problem in $\mathrm{x}$ ray optical components. In particular, for double-crystal monochromators, the use of silicon cooled with liquid gallium [1-3], silicon at cryogenic temperatures [4-5], the effect of crystal geometry (inclined [6-12], asymmetric [13], and thin crystals), and the use of diamond [14-15] instead of silicon are 
all currently being studied both experimentally and computationally. This document summarizes a series of finite element analyses (FEA) performed on room temperature silicon for the three standard APS sources, namely, a bending magnet, Wiggler $\mathrm{A}$, and Undulator $\mathrm{A}$. All modeling is performed with the silicon cooled directly with water or liquid gallium through rectangular channels. The temperature distribution and the maximum thermally induced deformations are presented. In all cases, we assume the monochromator to be the first optical component in the beamline. Obviously any arrangement, such as inclusion of a mirror as the first optical component, that reduces the power density and the total power incident on the crystal will improve its performance, albeit in some cases by transferring the thermal problem from one component to another. Clearly not every experimental configuration could be modeled, and so we present these findings as a starting point or guide for users in the design of the first optical components for their particular program requirements.

\section{Parameters used for FEA Calculations}

All thermal and structural analyses were performed using version 5.0a of the ANSYS code [16].

\section{A. The heat transfer coefficient}

The heat transfer coefficient, $h(T)$, is calculated using the following equation:

$h(T)=\frac{\operatorname{Nuk}(T)}{D_{h}}$,

where $\mathrm{Nu}$ is the Nusselt number, $\mathrm{D}_{\mathrm{h}}$ the hydraulic diameter, and $\mathrm{k}$ is the thermal conductivity of the coolant. 
For liquid gallium, the Lyon equation was used [17]:

$$
\mathrm{Nu}=7.0+0.025 \mathrm{R}_{\mathrm{e}}^{0.8} \mathrm{P}_{\mathrm{r}}^{0.8} \text {. }
$$

For water, the Gnielinski equation (valid for Reynolds numbers $\geq 2300$ ) was used [18]:

$$
\mathrm{Nu}=\frac{\left(\mathrm{R}_{\mathrm{e}}-1000\right) \mathrm{P}_{\mathrm{r}} f / 2}{\left.1.0+12.7\left(\mathrm{P}_{\mathrm{r}}^{2 / 3}-1\right)\right) \sqrt{f / 2}}
$$

$R_{\mathrm{e}}\left(=\rho v \mathrm{D}_{\mathrm{h}} / \mu\right)$ is the Reynolds number, with $\mathrm{v}$ the coolant velocity; $\mu$ and $\rho$ are the coolant dynamic viscosity and density, respectively, and $D_{h}$ is the hydraulic diameter; $P_{r}\left(=C_{p} \mu / k\right)$ is the Prandlt number, with $C_{p}$ the coolant heat capacity; $f$ is the friction coefficient and is given by the following formula [19]:

$$
f=\left\{1.58 \ln \left(\mathrm{R}_{\mathrm{e}}\right)-3.28\right\}^{-2} .
$$

The hydraulic diameter for rectangular channels can be evaluated using the following equation:

$$
D_{h}=\frac{2 w h}{(w+h)}
$$

where $w$ and $h$ are the channel width and height, respectively.

\section{B. Materials properties}

Some of the relevant thermophysical properties of silicon $\left(\right.$ at $20^{\circ} \mathrm{C}$ ) and liquid gallium (at $50^{\circ} \mathrm{C}$ ) are listed in Table 1. Figs. II.1a and b show the variation of the thermal conductivity and of the coefficient of thermal expansion of silicon as a function of temperature [20]. 
Table 1. Properties of silicon (at $20^{\circ} \mathrm{C}$ ) and liquid gallium (at $50^{\circ} \mathrm{C}$ ).

\begin{tabular}{|l|c|c|}
\hline Property & Silicon & Liquid gallium \\
\hline Thermal conductivity $\left(\mathrm{W} / \mathrm{cm}^{\circ}{ }^{\circ} \mathrm{C}\right)$ & 1.256 & 0.30 \\
Density $\left(\mathrm{kg} / \mathrm{m}^{3}\right)$ & 2330 & 6090 \\
Specific heat $(\mathrm{J} / \mathrm{kg}-\mathrm{K})$ & 754 & 343 \\
Thermal coefficient of expansion $\left({ }^{\circ} \mathrm{C}\right)$ & $2.33 \times 10^{-6}$ & $\mathrm{NA}$ \\
Dynamic viscosity $\left(\mathrm{N} \mathrm{s} / \mathrm{m}^{2}\right)$ & $\mathrm{NA}$ & $1.7 \times 10^{-3}$ \\
Young's modulus $(\mathrm{GPa})$ & 167.4 & NA \\
Poisson's ratio & 0.25 & NA \\
\hline
\end{tabular}


(a)

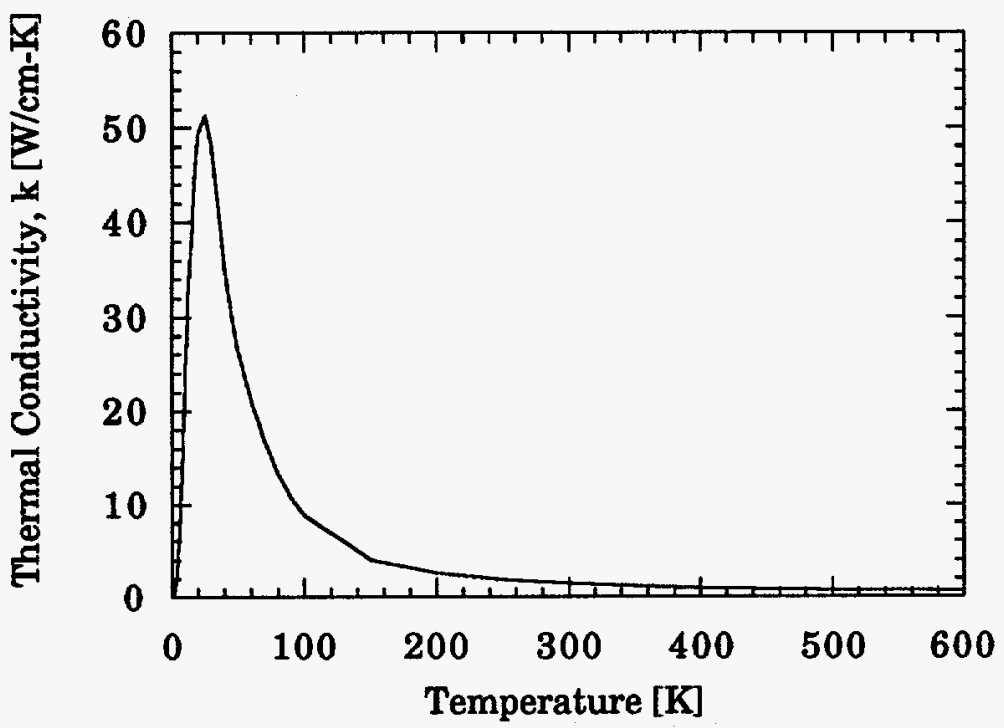

(b)

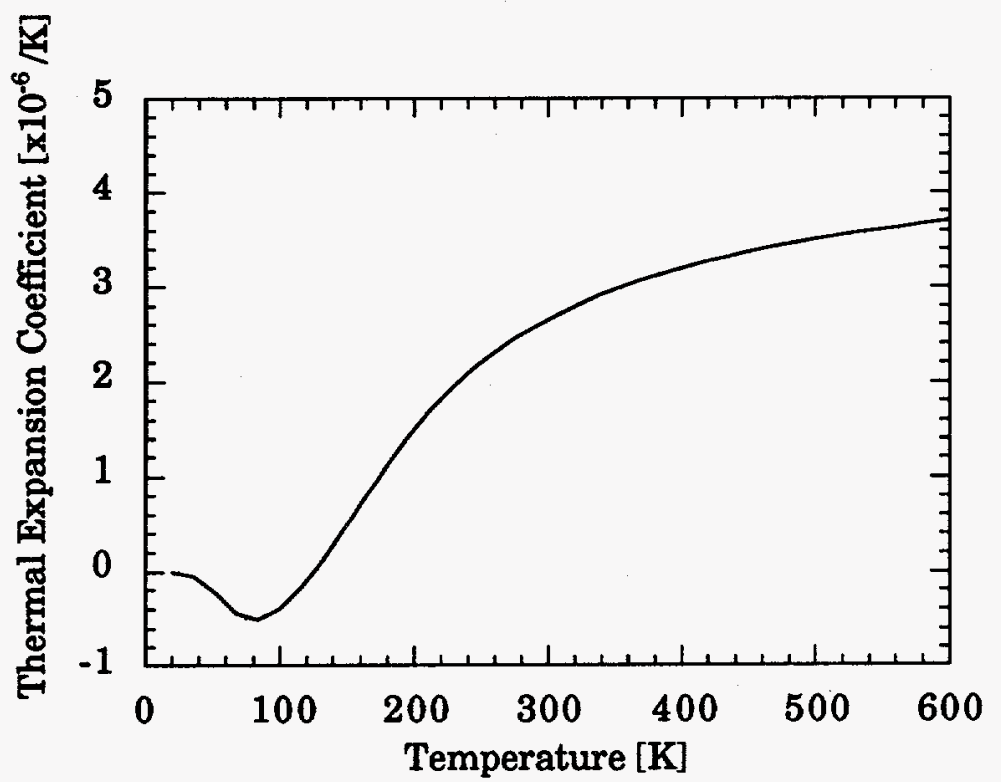

Fig. II.1: (a) Thermal conductivity, and (b) expansion coefficient of silicon as a function of temperature (data taken from Ref. 20). 


\section{The Bending-Magnet Monochromator}

\section{A. Properties of the source}

\section{Source parameters}

The bending magnet source parameters are summarized in Table 2 [21]:

Table 2. Bending-Magnet Source Parameters

\begin{tabular}{|l|c|}
\hline \multicolumn{1}{|c|}{ Parameter } & Value \\
\hline Ring energy, $\mathrm{E}_{\mathrm{r}}[\mathrm{GeV}]$ & 7.0 \\
\hline Positron beam current, $\mathrm{I}[\mathrm{mA}]$ & 100.0 \\
\hline Radius, $\mathrm{r}[\mathrm{m}]$ & 38.96 \\
\hline Magnetic field, $\mathrm{B}[\mathrm{T}]$ & 0.599 \\
\hline Critical energy, $\mathrm{E}_{\mathrm{c}}[\mathrm{keV}]$ & 19.5 \\
\hline Flux at $\mathrm{E}_{\mathrm{c}}[\mathrm{phot} / \mathrm{s} .0 .1 \%$ BW.mrad] & $1.12 \times 10^{13}$ \\
\hline Horizontal size, $\sigma_{\mathrm{x}}[\mathrm{mm}]$ & 0.114 \\
\hline Vertical size, $\sigma_{\mathrm{y}}[\mathrm{mm}]$ & 0.111 \\
\hline $1 / \gamma[\mu \mathrm{rad}]$ & 73 \\
\hline Power $[$ watts $/ \mathrm{mradH}-\mathrm{mA}]$ & 0.87 \\
\hline
\end{tabular}

2. Total power, heat flux, and source spectrum

At a ring energy of $7 \mathrm{GeV}$ and a current of $100 \mathrm{~mA}$, the bending magnet (BM) will radiate a total power of 86.7 watts per horizontal milliradian. The frontend components of the APS BM beamline were designed so that only $6 \mathrm{mrad}$ of the beam will be accepted. Hence, the total accepted power is about 520 watts. With an APS Be window assembly (two 0.250 -mm-thick beryllium windows), the peak normal heat flux at $30 \mathrm{~m}$ from the source is about 0.82 $\mathrm{W} / \mathrm{mm}^{2}$. Fig. III.1 shows the source spectral power for $1 \mathrm{~mA}$ current, 
integrated over the vertical angle. The two $\mathrm{Be}$ windows absorb about 0.110 $\mathrm{W} / \mathrm{mradH}-\mathrm{mA}$. Fig. III.2 gives the power density profile in the vertical direction at normal incidence at $30 \mathrm{~m}$, the monochromator location.

\section{B. Description and analyses of the crystal}

\section{Crystal geometry and coolant parameters}

The crystal geometry is sketched in Fig. III.3. It is directly cooled by flowing water through 51 rectangular channels. Each channel is $1 \mathrm{~mm}$ wide and 5 $\mathrm{mm}$ deep. The depth of $5 \mathrm{~mm}$ was chosen to keep the fin efficiency at a reasonable value and, at the same time, to maintain the water flow in a turbulent regime. The fins are also $1 \mathrm{~mm}$ thick each, and the base of the crystal was chosen so that it is thick enough $(30 \mathrm{~mm})$ to minimize the bowing of the crystal under the thermal load.

The distortions on the crystal surface are mainly determined by the amount of power deposited in the face plate. Therefore, to minimize the x-ray absorption, the face plate must be chosen to be as thin as possible. However, both the pressure-induced deformation and the fabrication aspects have to be considered. We found that a 0.5 - $\mathrm{mm}$-thick face plate is a good compromise (doubling the thickness will double the thermally induced slope error).

It has been seen both experimentally and computationally [22] that the periodicity of the channels and the fins results in a periodic variation of the temperature profile on the crystal surface, across the channels. This periodic variation of the temperature might eventually lead to a periodic slope error variation superimposed on the overall slope error due to the temperature gradient across the beam footprint. To avoid having this slope error structure in the tangential direction, the channels are oriented along the beam direction. However, the magnitude of this effect depends on the power load, the channel and fin geometry, the crystal face plate thickness, and the heat transfer coefficient.

The overall size of the crystal is $120 \mathrm{~mm} \times 102 \mathrm{~mm} \times 35.5 \mathrm{~mm}$, and this size is maintained throughout the analyses. However, because the BM power profile is uniform in the horizontal direction, only half of a channel-cell (see Fig. III.3) was used as a model in the finite element analysis. After comparison 
with a full crystal model, it was found that this assumption leads to slightly conservative results. However, the computation time is significantly reduced, and the error in terms of maximum slope error (which is the parameter we want to evaluate) is on the order of $15 \%$.

Because the magnitude of the power and the power density emitted by the bending magnet is low, water cooling is sufficient. For our analyses, we have chosen a flow rate of $5.5 \mathrm{gpm}$, flowing in 51 channels, which corresponds to a fluid velocity of about $1.39 \mathrm{~m} / \mathrm{s}$ and a Reynolds number of about 2700 . The heat transfer coefficient estimated using equations (1) and (3) is about 0.61 $\mathrm{W} / \mathrm{cm}^{2}-\mathrm{K}$. The coolant average temperature is set to $25{ }^{\circ} \mathrm{C}$, and its temperature rise along the channels is estimated to be on the order of $0.3{ }^{\circ} \mathrm{C}$.

\section{Power load and boundary conditions}

As mentioned previously, because the BM power profile is uniform in the horizontal direction, only half of a channel-cell was used to model the crystal. The absorbed power along the beam optical path is evaluated using PHOTON2 [23] by dividing the crystal into several layers and calculating the power density profile absorbed by each layer. Fig. III.4 shows the variation of the absorbed power density by a silicon crystal under the bending magnet beam, as a function of thickness. Calculations show that, for a $\mathrm{Si}(111)$ crystal set to diffract $4-\mathrm{keV}$ photons, about $54 \%$ of the incident power is absorbed in the 0.5 -mm-thick face plate. The remaining power (i.e., the fraction that is not reflected from the crystal surface or transmitted through the crystal base) is distributed between the fins, the coolant, and the base. The total absorbed power depends on the length of the optical path of the beam within the crystal, which depends on the Bragg angle and the crystal size.

The absorbed power is treated as a heat generation rate in the thermal analysis and is used to evaluate the temperature distribution and the corresponding distortion field. In all our calculations, the silicon is assumed to be isotropic, and the material properties are evaluated as a function of temperature. For the structural boundary conditions, the crystal is held at the center node (i.e., at $x=0, y=0, z=0$, see Fig. III.3), and, in order to avoid crystal rotation around the $x$-axis, the opposite node on the bottom face is restrained in the z-direction. Finally, the channel midplane is at the crystal 
plane of symmetry, and, in order to take into account the effect of the adjacent channels, all the nodes at the fin midplane are restrained in the $x$ direction.

\section{Temperature and distortion results}

The performance of the crystal was studied for x-ray energies from 4 to 24 keV. The thermal and structural results are summarized in Table 3. For comparison, the Darwin width for the symmetric Si(111) reflection for each energy is also given. Fig. III.5 shows the isotherms for a $\mathrm{Si}(111)$ crystal set to diffract 4-keV photons (Bragg angle $=29.6^{\circ}$ ). Fig. III.6 shows the displacement and slope error profile along the center line of a $\mathrm{Si}(111)$ crystal set to diffract 4-keV photons. Note that a $30-\mathrm{mm}$-thick base was enough to reduce the bowing component to a minimum (the slope profile goes back to zero at the edges of the crystal). The crystal distortion profile is, therefore, mainly due to the temperature distribution on the crystal surface. At $4 \mathrm{keV}$, which corresponds to the highest heat flux, the increase in temperature above that of the coolant $\left(25^{\circ} \mathrm{C}\right)$ is about $7.5^{\circ} \mathrm{C}$, and the total thermally induced slope error is only about $26 \%$ of the Darwin width. At higher photon energies (lower incidence angles), although the surface power density is lower, the total absorbed power is much higher due to the increased optical path as the beam traverses the crystal. This impacts on the thermally induced slope errors: at $8 \mathrm{keV}$ (Bragg angle $=14.3^{\circ}$ ), the thermally induced slope error is $32 \%$ of Darwin width, while at $24 \mathrm{keV}$ (Bragg angle $=4.7^{\circ}$ ), it is equal to $40 \%$. However, at high photon energies, one can certainly improve the crystal performance by using appropriate filters to cut off all the power from lower energy $x$-rays, which would be otherwise absorbed in the face plate.

Finally, remember that the above analyses are based on a crystal with a cooled area that is $102 \mathrm{~mm}$ wide (51 channels). Reducing the width of the crystal will increase the fluid velocity (fewer channels), and accordingly it increases the heat transfer coefficient for the fixed flow rate of $5.5 \mathrm{gpm}$. As an example, calculations were performed for a $62-\mathrm{mm}$ crystal (29 channels

and about 2-mrad horizontal beam opening). For the $4 \mathrm{keV}$ case, the thermally induced slope error is reduced to about $17 \%$ of the Darwin width, while at $24 \mathrm{keV}$ it is reduced to about 23\%. Fig. III.7 shows the variation of 
the thermally induced slope error as a function of Bragg's angle for both cases.

\section{Conclusion}

Our simulations show that a water-cooled $\mathrm{Si}(111)$ slotted crystal will perform acceptably under the heat load from the APS bending-magnet beam. The effective slope error for the 4-keV case, which corresponds to the highest heat flux on the crystal surface, is only about $26 \%$ of the Darwin width. For higher energies, the ratio of the total slope error to the Darwin width is larger due to the increase in the power absorbed by the face plate (lower incidence angle) along with the decrease of the Darwin width. However, in this case, one can certainly further reduce the distortions by using appropriate filters to cut off the power load from lower energy $x$-rays.

The modeled crystal was wide enough $(102 \mathrm{~mm}$ ) to intercept about $3.4 \mathrm{mrad}$ of the horizontal beam opening. If a smaller crystal was used with the same flow rate, much higher fluid velocities, and hence better heat transfer properties could be obtained. As an example, we performed the analysis for a 62-mm-wide crystal, the thermally induced slope errors were reduced by 35 to $45 \%$ compared to the case of the $102-\mathrm{mm}$ crystal (see Fig. III.7). The same performance can be achieved by simply increasing the flow rate. However, the increase in the fluid velocity may be limited because of the flow-induced vibrations. In the extreme case, further improvement can be obtained by using liquid gallium as a coolant instead of water. Liquid gallium gives much higher heat transfer coefficients for a fixed flow rate compared to water. With water as a coolant, enhanced heat exchangers, such as the pin-post [24], microchannel design [25-26], or cooling channels filled with porous medium [27], should also be considered.

Finally, the analysis is conservative in the sense that all the power lost from the incident beam is converted into heat. No attempt was made to consider losses from Compton scattering, and hence we expect that a water-cooled slotted crystal will perform even better than predicted here from this analysis. 
Table 3: The bending-magnet monochromator: Temperature and distortion results. PHF is the peak heat flux on the crystal surface, $\mathrm{T}_{\max }$ is the maximum temperature on the crystal surface, $\mathrm{Tbtf}$ is the maximum temperature at the bottom of the face plate, $\Delta \mathrm{T}_{\max }$ is the maximum temperature rise above the coolant temperature $\left(25^{\circ} \mathrm{C}\right)$. The total slope error is defined as a peak-to-peak value of the slope profile. The Si(111) Darwin width is given for comparison.

\begin{tabular}{|c|c|c|c|c|c|c|c|}
\hline $\begin{array}{c}\text { Energy } \\
{[\mathrm{keV}]}\end{array}$ & $\begin{array}{c}\theta_{\mathrm{Bragg}} \\
{[\mathrm{deg} .]}\end{array}$ & $\begin{array}{c}\mathrm{PHF} \\
{\left[\mathrm{W} / \mathrm{mm}^{2}\right]}\end{array}$ & $\begin{array}{c}\mathrm{T}_{\max } \\
{\left[{ }^{\circ} \mathrm{C}\right]}\end{array}$ & $\begin{array}{c}\mathrm{T}_{\mathrm{btf}} \\
{\left[{ }^{\circ} \mathrm{C}\right]}\end{array}$ & $\begin{array}{c}\Delta \mathrm{T}_{\max } \\
{\left[{ }^{\circ} \mathrm{C}\right]}\end{array}$ & $\begin{array}{c}\text { Maximum } \\
\text { slope } \\
{[\mu \mathrm{rad}]}\end{array}$ & $\begin{array}{c}\text { Darwin } \\
\text { width } \\
{[\mu \mathrm{rad}]}\end{array}$ \\
\hline 4 & 29.6 & 0.40 & 32.5 & 32.4 & 7.5 & 20.0 & 76 \\
\hline 8 & 14.3 & 0.20 & 30.0 & 29.9 & 5.0 & 11.0 & 33.9 \\
\hline 16 & 7.1 & 0.10 & 28.2 & 28.1 & 3.2 & 6.0 & 16.6 \\
\hline 24 & 4.7 & 0.07 & 27.3 & 27.2 & 2.3 & 4.5 & 11.0 \\
\hline
\end{tabular}




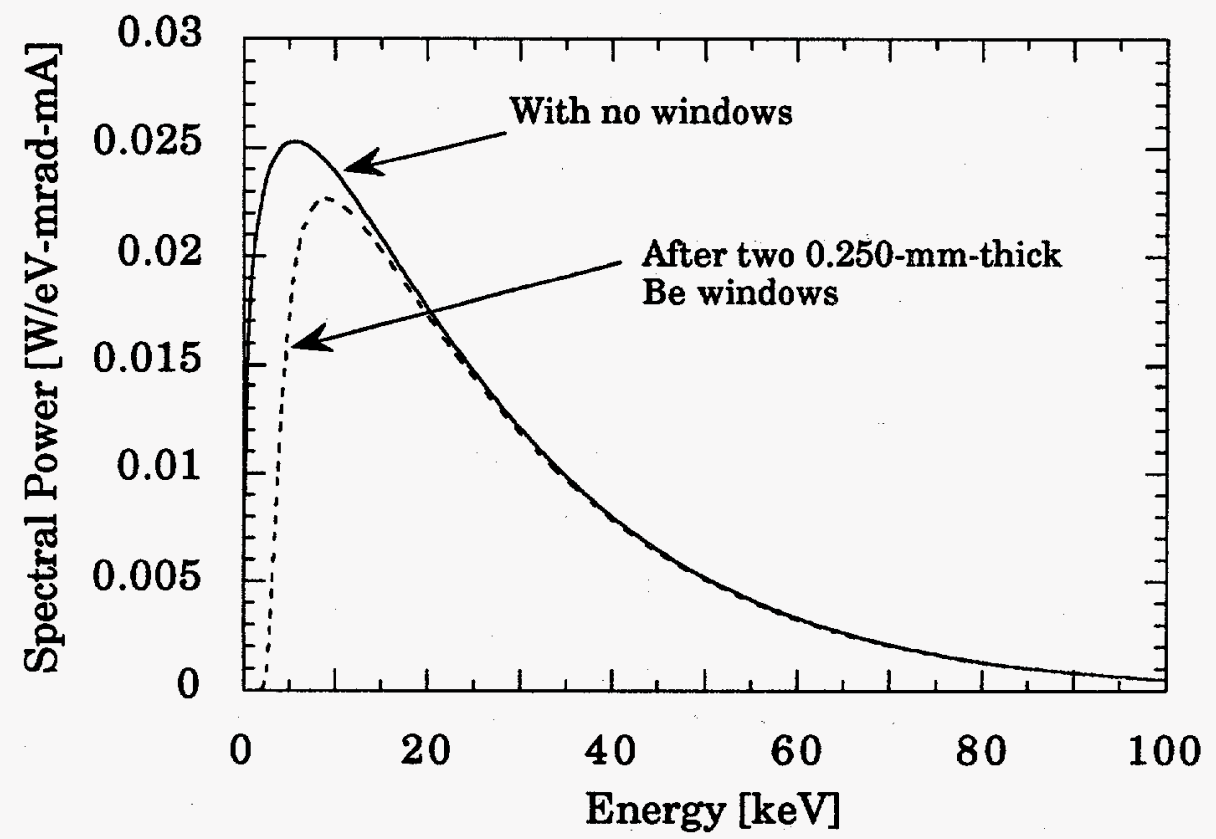

Fig. III.1: The APS bending magnet spectral power before and after two $0.250-\mathrm{mm}$-thick Be windows, at a ring energy of $7 \mathrm{GeV}$. The integration was done over the vertical angle only. 


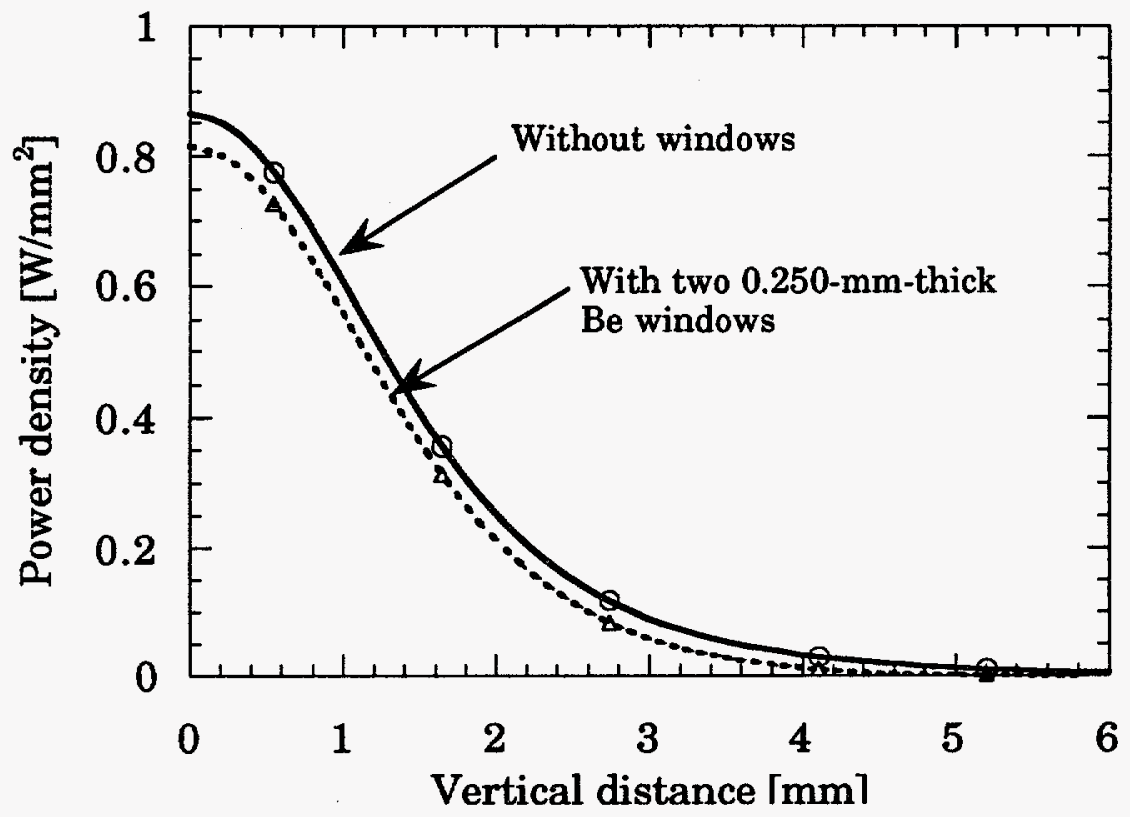

Fig. III.2: The APS bending magnet spatial power density profile in the vertical direction, at $30 \mathrm{~m}$ from source, at normal incidence, for a ring energy of $7 \mathrm{GeV}$ and a current of $100 \mathrm{~mA}$. 


\section{Perspective view}

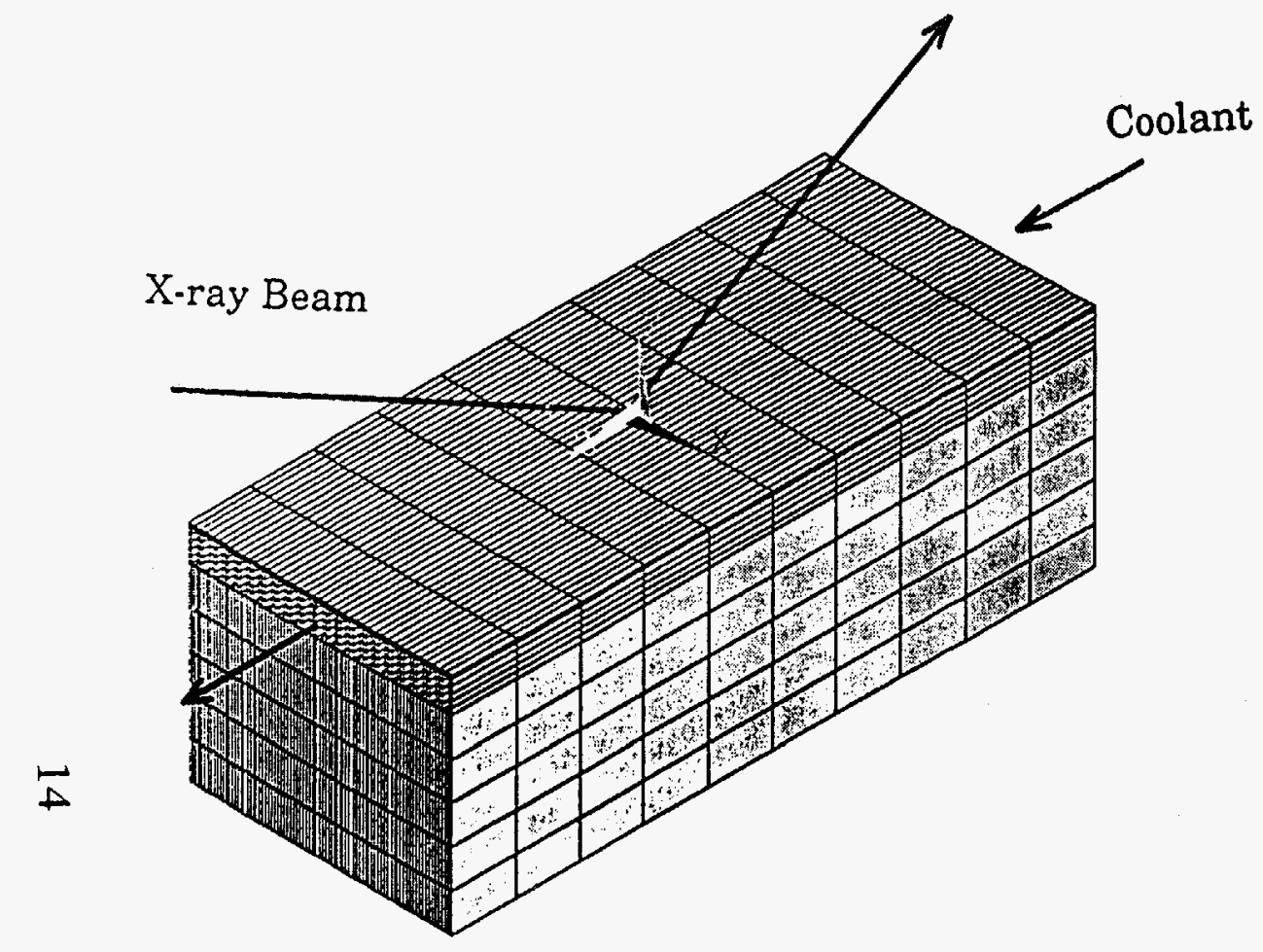

End view

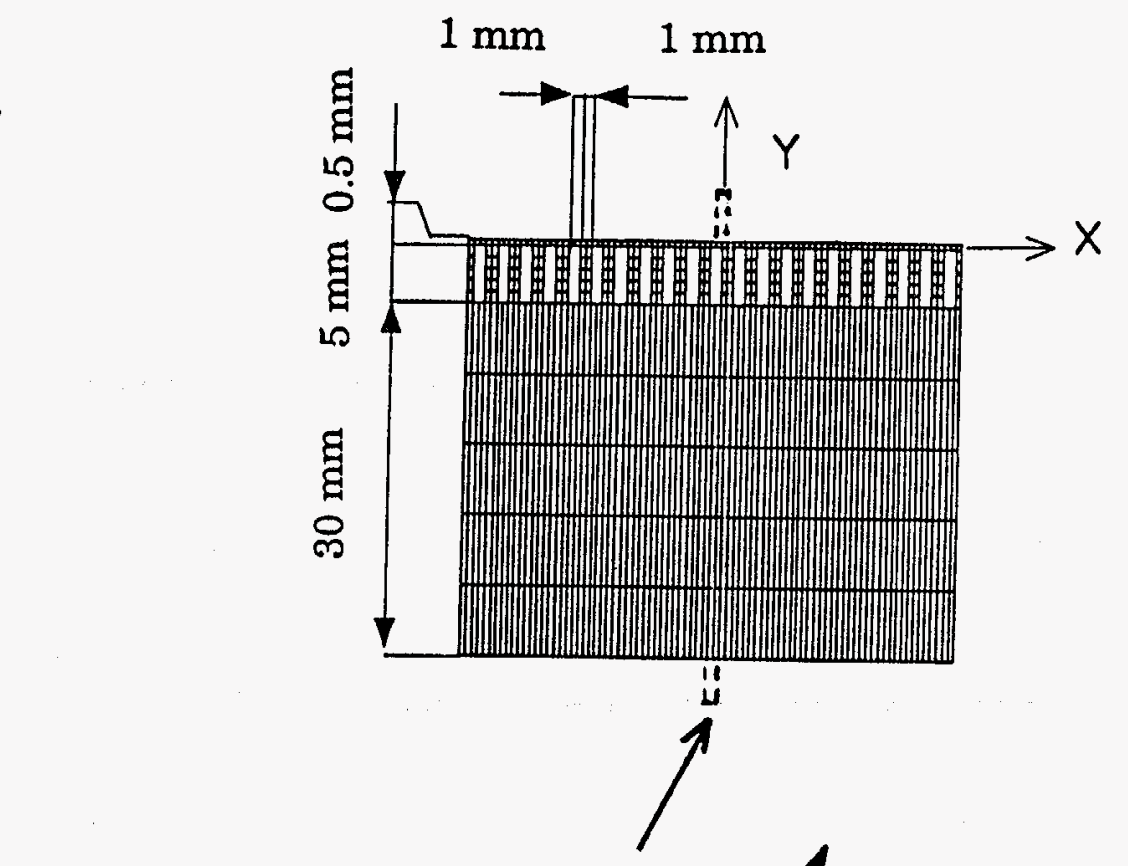

Fig. III.3: The crystal geometry chosen for the finite element analysis. For clarity, the exact number of channels and elements is not shown. Because the bending magnet beam power profile is uniform in the horizontal direction only one channel-cell was used to model the crystal.

The simulated channel-cell 


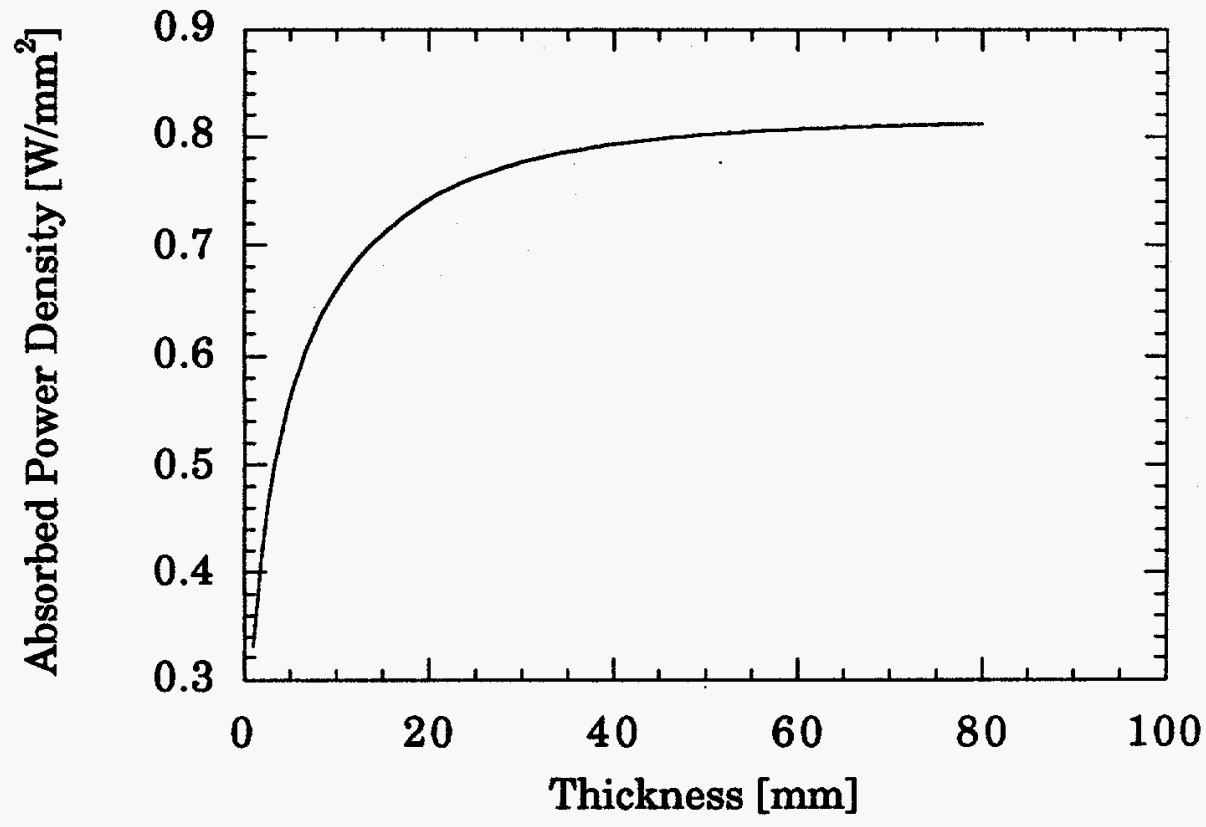

Fig. III.4: Absorbed power density, as function of thickness, at $30 \mathrm{~m}$ from source, by a silicon crystal subjected to an APS bending magnet beam operating at $7 \mathrm{GeV}$ and $100 \mathrm{~mA}$. The calculation was performed by dividing the crystal into several layers and calculating the difference between the incident and the absorbed power density for each layer. 


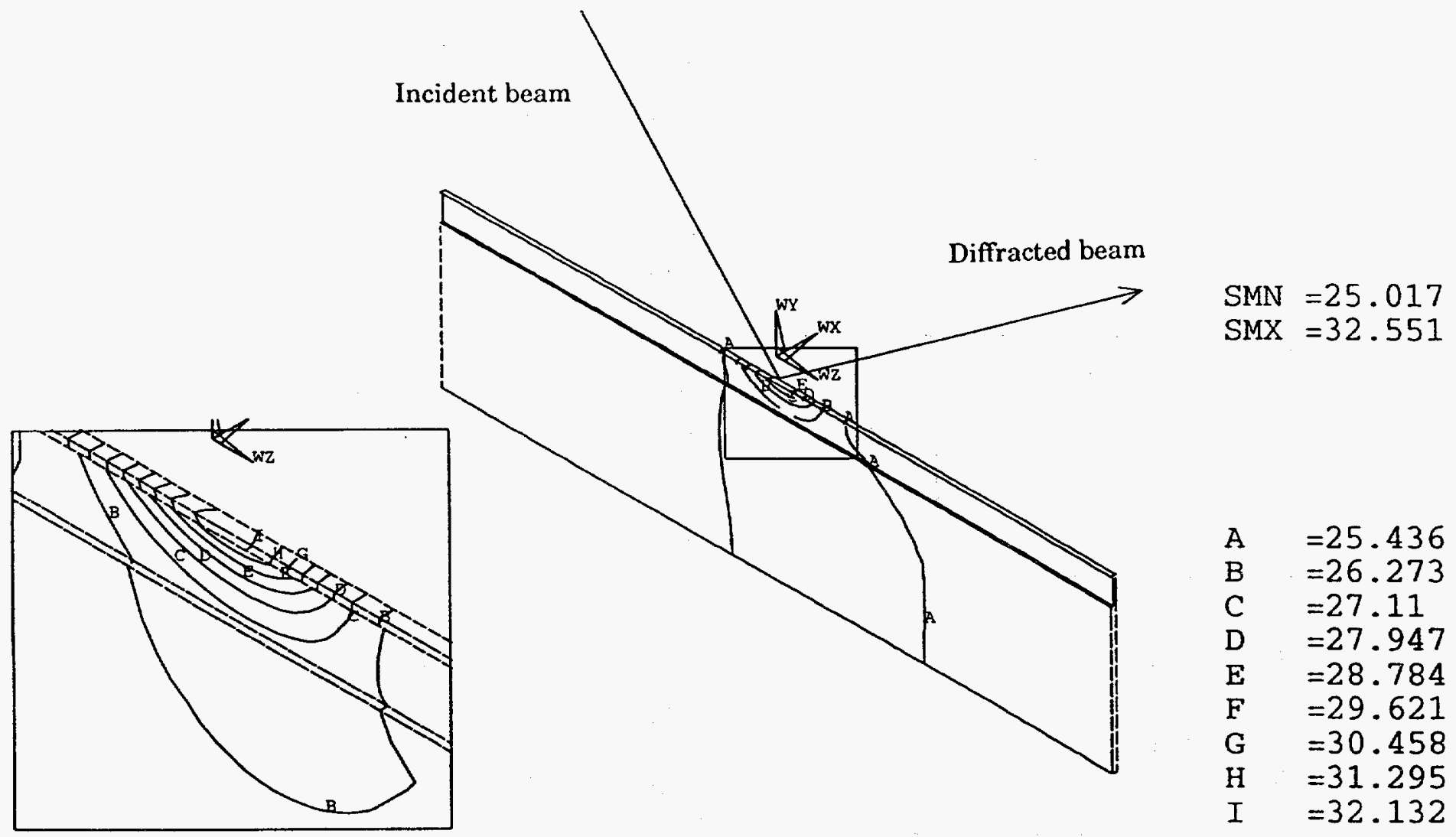

Fig. III.5: Temperature profile, in ${ }^{\circ} \mathrm{C}$, within a $\mathrm{Si}(111)$ crystal oriented to diffract 4-keV photons. The plot shows the simulated channel-cell, which is located at the crystal center line, along the beam direction. For clarity, the coordinate system is offset in the y-direction. SMX and SMN are the maximum and the minimum temperatures, respectively. 


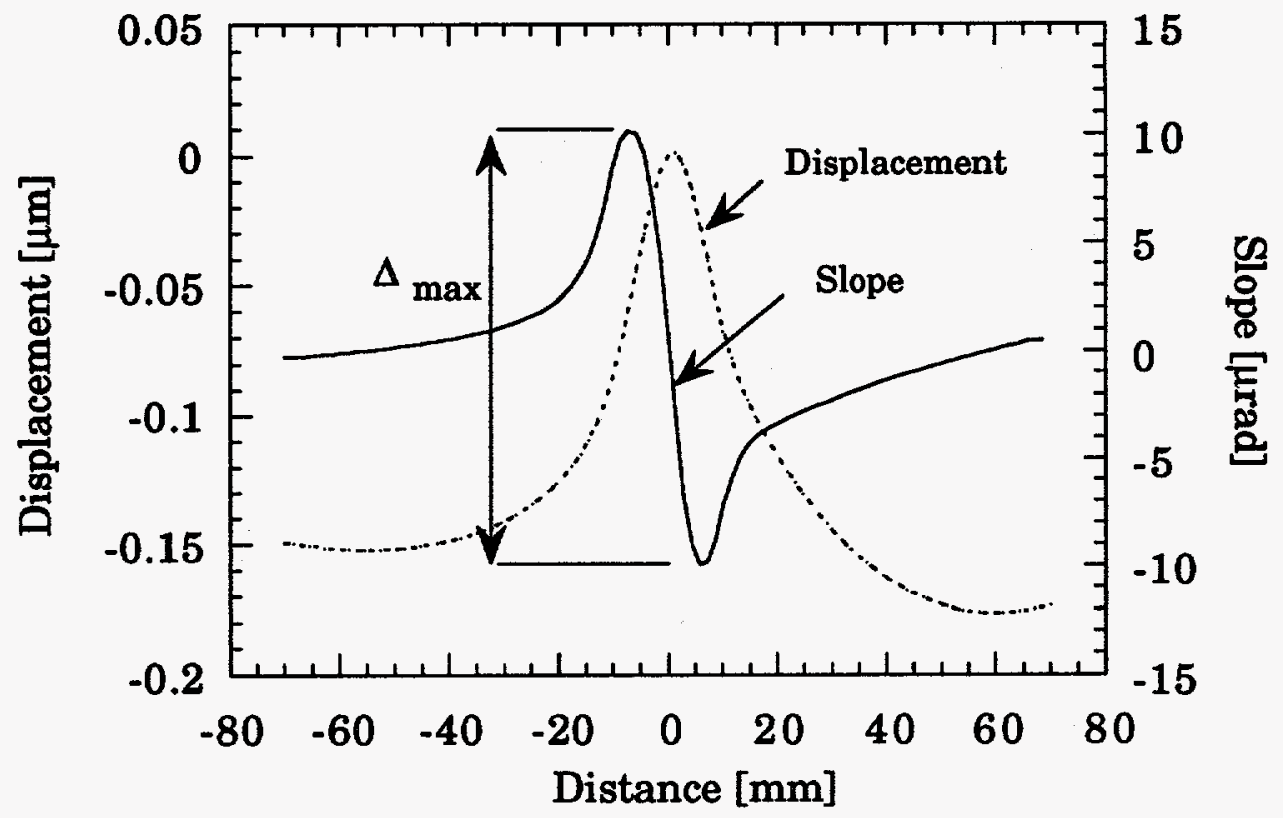

Fig. III.6: Displacement and tangential slope error profile along the center line of a $\mathrm{Si}(111)$ crystal oriented to diffract $4-\mathrm{keV}$ photons from the APS bending magnet source at $30 \mathrm{~m}$ from source. Calculations are for $7 \mathrm{Gev}$ and $100 \mathrm{~mA}$ operation. 


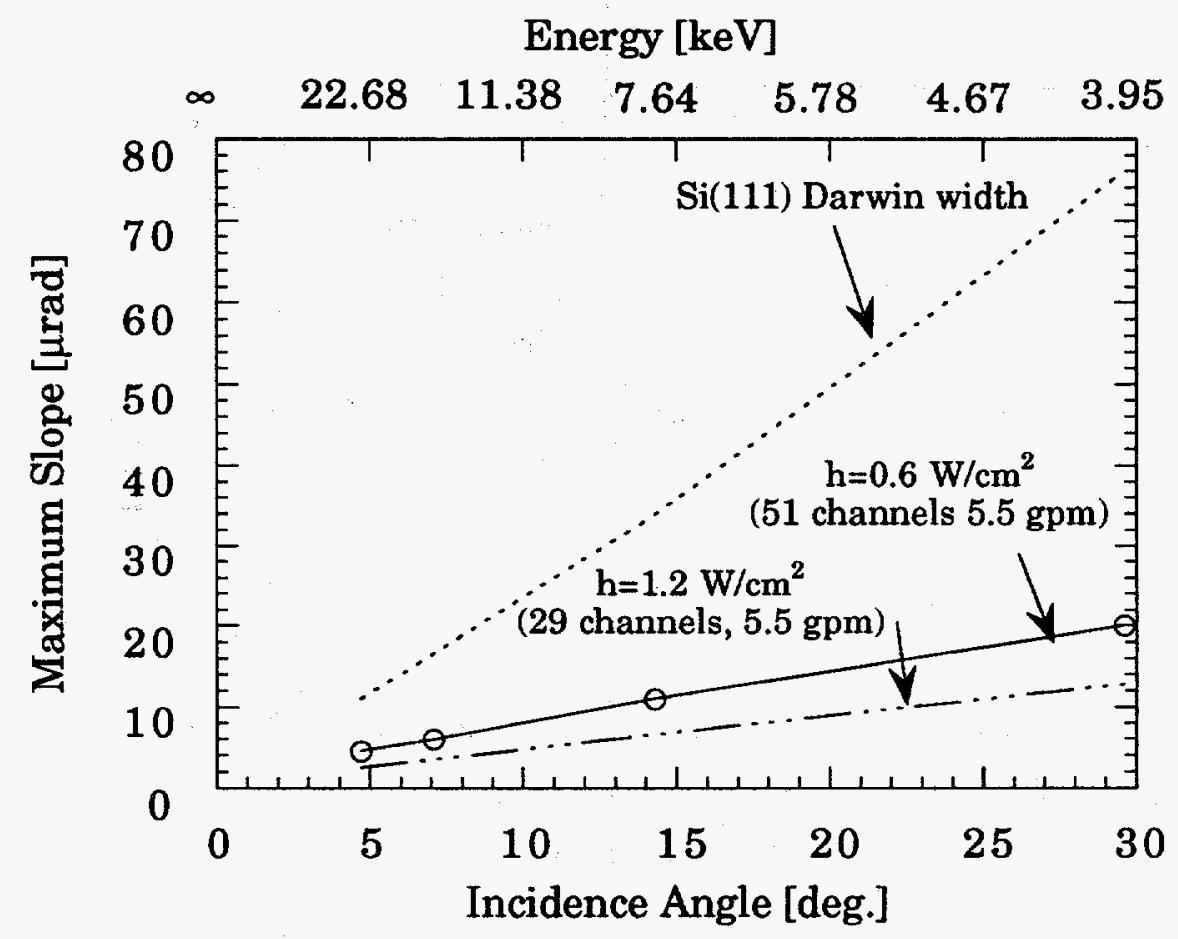

Fig. III.7: The bending-magnet monochromator: Variation of the total thermally induced slope error as a function of Bragg's angle (bottom axis) and the corresponding energy (top axis) for a $\mathrm{Si}(111)$ crystal. The results are plotted for crystals with 51 and 29 channels with a fixed flow rate of $5.5 \mathrm{gpm}$ of water. For comparison the $\mathrm{Si}(111)$ Darwin width is also shown. 


\section{A. Properties of the source}

\section{Wiggler A parameters}

The detailed characteristics of Wiggler A can be found in reference [28]; some of the important parameters for a gap of $2.1 \mathrm{~cm}$ are listed in Table 4 .

Table 4. Wiggler A Parameters for a 2.1-cm Gap.

\begin{tabular}{|l|c|}
\hline Parameter & Value \\
\hline Wavelength, $\lambda[\mathrm{cm}]$ & 8.5 \\
\hline Number of Periods, $\mathrm{N}$ & 28 \\
\hline Device Length, $\mathrm{L}[\mathrm{m}]$ & 2.4 \\
\hline Magnetic Gap $[\mathrm{cm}]$ & 2.1 \\
\hline Deflection Parameter, $\mathrm{K}$ & 7.9 \\
\hline Maximum Field, $\mathrm{B}_{\mathrm{eff}}[\mathrm{T}]$ & 1.0 \\
\hline Critical Energy, $\mathrm{E}_{\mathrm{c}}[\mathrm{keV}]$ & 32.6 \\
\hline Total Power $[\mathrm{kW}]$ & 7.4 \\
\hline Peak Power Density $\left[\mathrm{kW} / \mathrm{mrad}^{2}\right]$ & 73.0 \\
\hline
\end{tabular}

2. Total power, heat flux, and source spectrum

The total power emitted by Wiggler A with a 2.1-cm magnetic gap at a ring energy of $7 \mathrm{GeV}$ and $100 \mathrm{~mA}$ current is about $7.4 \mathrm{~kW}$. The standard APS front-end configuration for a wiggler beamline contains two $0.250-\mathrm{mm}$-thick beryllium windows at $25 \mathrm{~m}$ from source. These beryllium windows are protected by two $0.300-\mathrm{mm}$-thick graphite filters located at $22 \mathrm{~m}$ from the source. Fig. IV.1 shows the source power spectrum for $K=7.94$. (Note that the 
graphite filters absorb most of low energy photons, particularly below $5 \mathrm{keV}$.) Fig. IV.2 shows the corresponding power density profile at $30 \mathrm{~m}$ from source, the monochromator location. At this distance, the peak normal heat flux after the windows and filters is about $75 \mathrm{~W} / \mathrm{mm}^{2}$, and the beam size is about $29 \mathrm{~mm}$ (horizontal FWHM) by $2.7 \mathrm{~mm}$ (vertical FWHM).

\section{B. Description and analyses of the crystal}

\section{Crystal geometry and cooling parameters}

The geometry used for the finite element model is similar to that of the bending magnet crystal (see Fig. III.3), except that the height of the channels was reduced to $3 \mathrm{~mm}$ and liquid gallium is used as a coolant. A smaller channel height was chosen because of the better thermal conductivity of liquid gallium. Additionally, in order to reduce the pressure-induced deformation due to the liquid-gallium flow, the thickness of the crystal face plate was increased to $0.7 \mathrm{~mm}$.

The coolant flow rate was chosen to be $4 \mathrm{gpm}$, flowing in 17 channels. This corresponds to a fluid velocity of about $4.95 \mathrm{~m} / \mathrm{s}$. The heat transfer coefficient, evaluated using Lyon's equation (Eq. 2), is about $21.8 \mathrm{~W} / \mathrm{cm}^{2}-\mathrm{K}$. The average coolant temperature was set to $50^{\circ} \mathrm{C}$.

Here also, one half channel was used to compute the maximum distortions on the crystal surface under the Wiggler A beam. The goal of this study is to evaluate the maximum distortions of the crystal surface in the direction of the $x$-ray beam (tangential slope error). The maximum temperature gradient and, consequently, the maximum thermally induced slope error occur at the crystal midplane. Therefore, the channel located along the crystal center line was used for the finite element model. As mentioned in the bending magnet section, this approach saves considerable computation time and leads to only slightly conservative results (about $15 \%$ error in terms of thermally induced slope error) compared to those for the full crystal model. Note, however, that the performance of a monochromator is ultimately measured by its rocking curve. Experimentally, a rocking curve is obtained by recording the intensity of the diffracted beam from the second crystal of a double-crystal monochromator, by rocking its angle. Computationally, it can be obtained 
from the calculated distortion profile of the entire crystal, and therefore one needs to model one half of the crystal. This task will be performed in the near future.

\section{Power load and boundary conditions}

The power deposited in the crystal was computed following the same procedure as for the bending magnet case. The crystal was divided into several layers, and the power density profile absorbed by each layer along the beam optical path was calculated. Fig. IV.3 shows the variation of the absorbed power density as a function of thickness for a silicon crystal subjected to the Wiggler $A$ beam at a $2.1-\mathrm{cm}$ gap. These calculations took into account the standard windows and filters. The total power deposited in these filters and windows is about 1370 watts (1296 watts for the filters and 74 watts for the windows). The total incident power at the monochromator is about $5.72 \mathrm{~kW}$ and the peak heat flux is about $75 \mathrm{~W} / \mathrm{mm}^{2}$.

Here, because a large amount of power is contained in the high energy $x$-rays, assuming surface absorption of the entire incident beam is unrealistic. This is particularly true at large incidence angles (low x-ray energies) where the beam path length through the face plate is shorter. For the Wiggler $\mathrm{A}$ beam at 2.1-cm magnetic gap, when surface absorption of the entire incident beam is assumed, the FEAs predict melting for a $\mathrm{Si}(111)$ crystal set to diffract 4$\mathrm{keV}$ photons (Bragg's angle $=29.62^{\circ}$ ). For the chosen geometry, the face plate absorbs only about $40 \%$ of the incident power. A large fraction of the transmitted $x$-ray beam through the face plate will fall in the channels and will be absorbed and transported by the liquid gallium (a relatively high- $Z$ material). Calculations performed using PHOTON2 showed that, for the case of $4 \mathrm{keV}$ reflection, only $6 \%$ of the incident peak power density remains after the beam traverses the coolant. Note, however, that our calculations are conservative in a sense that no attempt was made to consider the loss of power from Comptpon scattering.

All the analyses were performed assuming a Wiggler A beam at $2.1-\mathrm{cm}$ gap $(\mathrm{K}=7.94, \mathrm{Ec}=32.6 \mathrm{keV})$. The power absorbed is treated as a heat generation rate in the thermal analysis. The absorbed power by the coolant was taken into account. The power distribution was used to evaluate the temperature 
distribution and the corresponding distortion field. The structural analysis boundary conditions are the same as for the bending magnet crystal (see Section III.B).

\section{Temperature and distortion results}

The performance of the crystal was studied as a function of Bragg angle. Table 5 summarizes the FEA results. Fig. IV.4 shows the temperature profile as the beam traverse the crystal. The crystal was set to diffract $8-\mathrm{keV}$ photons from (111) planes (14.3 ${ }^{\circ}$ Bragg angle). As we can see from this figure, some heating occurs in the crystal base, along the beam path, and near the back surface. As a result, the crystal bows upward, compensating to some degree the distortions due to the power deposited on the crystal surface. This an evidence that one might design adaptive optics that use the heat load from synchrotron radiation itself. Fig. IV.5 shows the variation of the effective thermally induced slope error as a function of the beam incidence angle at 2.1-cm magnetic gap. For comparison, the symmetric $\mathrm{Si}(111)$ Darwin width and the corresponding energy are also plotted. For example, for a $\mathrm{Si}(111)$ crystal set to diffract $8-\mathrm{keV}$ photons (Bragg angle of $14.3^{\circ}$ ), the total thermally induced slope error would be about $54 \mu \mathrm{rad}$, compared with the intrinsic Darwin width of about $34 \mu \mathrm{rad}$.

The FEA results plotted in Fig. IV.5 suggest that the use of slotted Si(111) crystals with gallium cooling and with a 2.1-cm-gap Wiggler A will lead to severe thermal distortions for x-ray energies below $20 \mathrm{keV}$. At about $16 \mathrm{keV}$ ( $7^{\circ}$ incidence angle), the thermally induced slope error becomes comparable to the Darwin width, while at $24 \mathrm{keV}$, the slope error becomes larger than the Darwin width again. At low incidence angles (higher energies), although the surface power density is lower, the total absorbed power is much higher due to the increased optical path as the beam traverses the crystal. These simulations clearly show that, for the APS Wiggler A, additional methods for reducing the power load are required; some of the possible options are proposed below. 


\section{Asymmetrically cut crystal option}

Fig. IV.5 indicates that, in order to minimize thermal slope errors, one should work at low incidence angles. Depending on the scanning range required, this can be done by using an asymmetrically cut crystal. However, note that the use of asymmetric crystals in a double-crystal monochromator also entails a greater sensitivity to thermal distortions. This, together with energy tunability range and an increased photon acceptance of the asymmetric crystal are all issues that have to be weighed when considering the use of asymmetric crystals. An asymmetrically cut monochromator with adjustable asymmetry is currently under development at the APS [13]. This monochromator will allow one to increase the energy scanning range, and at the same time, to spread the beam footprint on the crystal surface [13].

\section{Gap opening and filter options}

Depending on the energy, a possible ways to reduce the power load are to open the wiggler gap or use filters or a combination of both. In this section, we describe various scenarios related to the gap opening and the use of filters. Fig. IV.6 shows the plot of the normal incidence peak heat flux at 30 $\mathrm{m}$ from source as a function of the deflection parameter. Figs. IV.7 and 8 show the brilliance and integrated flux as a function of energy for several gap sizes.

From Fig. IV.7, it can be seen that the peak brilliance of the wiggler beam is independent of the magnetic gap opening. Thus, if beam brilliance is the parameter of interest, the user should set the brilliance peak to the interested energy. For energies below $32 \mathrm{keV}$, this will mean a gap size larger than 2.1 $\mathrm{cm}$. In addition to increasing the brilliance, opening the wiggler gap also dramatically reduces the heat flux on the crystal. However, as shown in Fig. IV.8, opening the gap reduces the total incident photon flux.

As an example, we studied the case in which the user is interested in $10-\mathrm{keV}$ photons. Table 6 summarizes the results of the various scenarios. By opening the wiggler gap so that the peak brilliance occurs at $10 \mathrm{keV}(\sim \mathrm{K}=2.44)$, the gain in brilliance incident on the crystal over that of the 2.1-cm gap $(\mathrm{K}=7.94)$ is about $30 \%$. In addition, the surface peak heat flux (assuming an incidence 
angle of $11.4^{\circ}$ ) on the crystal drops from $14.8 \mathrm{~W} / \mathrm{mm}^{2}$ to $3.6 \mathrm{~W} / \mathrm{mm}^{2}$. The total power impinging on the crystal also drops from $5.8 \mathrm{~kW}$ to about $0.35 \mathrm{~kW}$ (the absorption by the graphite filters and windows is taken into account). This will greatly reduce the thermal distortions on the crystal. Thus, by opening the wiggler gap, the brilliance of the $10-\mathrm{keV}$ photons impinging on the crystal is increased, and, due to the smaller thermal distortions (compared to the case of $\mathrm{K}=7.94$ ), the brilliance will be better preserved through the monochromator. However, as seen in Fig. IV.8, the total number of $10-\mathrm{keV}$ photons produced by a $\mathrm{K}=2.44$ wiggler is only about $25 \%$ that for the case where $K=7.94$. On the other hand, due to the severe heat flux for the case of $\mathrm{K}=7.94$, the thermal distortions would certainly reduce the photon flux throughput. Thus, it may be that, realistically, the open gap situation may actually yield not only increased brilliance but increased total photon flux through the monochromator as well.

Now, let us assume that we are interested in maximizing the total number of $10-\mathrm{keV}$ photons through the monochromator. Additionally, we assume that we can tolerate total slope errors on the crystal of about half of the intrinsic $\mathrm{Si}$ (111) Darwin width for that energy. Based on the results of the FEA studies, we compared the total flux incident on the crystal from opening the gap and leaving the gap closed $(2.1 \mathrm{~cm})$, but using filters to reduce the heat load. Fig. IV.9 shows the results of calculations using PHOTON2 simulating the flux at a $2.1-\mathrm{cm}$ gap $(\mathrm{K}=7.94)$ with and without various filters and the flux at opened gap with $K=3.88$. The flux and power densities are given after the standard $0.600 \mathrm{~mm}$ of graphite filters and $0.500 \mathrm{~mm}$ of Be windows, at 30 $\mathrm{m}$ from the source. The gap opening and the filters were chosen so that, with the crystal at an incidence angle of $11.4^{\circ}(10 \mathrm{keV}, \mathrm{Si}(111))$, the surface power density on the crystal would be about $6.4 \mathrm{~W} / \mathrm{mm}^{2}$. This surface power density was chosen based on the FEA studies (Fig. IV.5), and it corresponds to a thermal distortion of about $14 \mu \mathrm{rad}$ on the crystal (about $52 \%$ of the Darwin width). Note that the actual thermal distortions should be less because the FEA studies were based on the case where $K=7.94$ and the total power was about $7.4 \mathrm{~kW}$; whereas the total power after the filters or a more open wiggler gap will be considerably less. The flux for the closed gap ( $K=7.94)$ without filters is shown for comparison. Fig. IV.9 shows that, if one is interested in working at $10 \mathrm{keV}$ with $\mathrm{Si}(111)$ and can tolerate a $14-\mu \mathrm{rad}$ total thermal 
distortion, it is much better to open the gap of the wiggler than to use filters with a closed gap. The filters would absorb all the desired $10-\mathrm{keV}$ photons. In this case, the flux (for $10-\mathrm{keV}$ photons) incident on the crystal at $\mathrm{K}=3.88$ is about $40 \%$ of that at $K=7.94$ with no filter.

However, if the user is interested in higher energies ( $>25 \mathrm{keV}$ ), the use of filters may be a better option for maximum flux. Note that the above only compares the flux incident on the crystal and not the actual flux after the crystal. To predict the actual flux after the crystal would require a detailed ray-tracing simulation, possibly using SHADOW [29], that incorporates the thermal distortions of the crystals. Clearly, a case-by-case study to optimize brilliance and/or flux is necessary.

Other alternative approaches include the use of a mirror as the first optical component [30], or cryogenically cooled thin crystals. Mirrors operate at much smaller incidence angles than Bragg reflections, therefore the heat fluxes are less severe. They can be used to cut off higher energy photons, thereby reducing the power load on the monochromator. Thin crystals have the advantage of absorbing less power and, when cooled with liquid nitrogen, may offer a solution. We are currently investigating this.

\section{Conclusion}

We have performed simulations for a liquid-gallium-cooled, slotted $\mathrm{Si}(111)$ crystal subjected to the Wiggler A radiation in the worst-case scenario: a 2.1cm magnetic gap, $\mathrm{K}=7.94$ with a critical energy at $32.6 \mathrm{keV}$ (for $7 \mathrm{GeV}-100$ $\mathrm{mA}$ operation). The FEA results clearly show that the use of $\mathrm{Si}(111)$ crystals with the chosen cooling scheme for the classical energy region of 4-20 keV will result in severe thermal distortions. Depending on the beam parameter of interest, energy, brilliance or total flux, and on the amount of distortion that is tolerable in the crystal, we have proposed various options. In the low energy range, the best option to reduce the heat load is to open the Wiggler $A$ gap. As an example, setting the wiggler at a gap of $4.75 \mathrm{~cm}(\mathrm{~K}=2.44)$ will reduce the peak heat flux on the crystal surface to the point at which it can be handled by a slotted crystal with liquid-gallium cooling. The FEA calculations indicate that, in this case, the maximum slope error for a crystal set to diffract $10-\mathrm{keV}$ photons (Bragg's angle $=11.4^{\circ}$ ), is about $12.5 \mu \mathrm{rad}$ (see 
Table 6) compared to the Darwin width of $27 \mu \mathrm{rad}$ for the $\mathrm{Si}(111)$ reflection. For this particular Wiggler A gap value of $4.75 \mathrm{~cm}$, the brilliance of the 10$\mathrm{keV}$ photons is optimized at the expense of the incident flux on the crystal. However, depending on the amount of distortion that is tolerable, by setting the wiggler gap to a lower value (higher $\mathrm{K}$ ) one may optimize the total number of $10-\mathrm{keV}$ photons through the crystal. Detailed ray-tracing simulations will be required to predict the optimum $\mathrm{K}$ value that would yield a maximum photon throughput. Either way, opening the wiggler gap significantly reduces the heat load on the crystal. In the high energy range ( $>25 \mathrm{keV}$ ), the use of filters may be more appropriate. Here, opening the gap (from $2.1 \mathrm{~cm}$ ) will reduce both the brilliance and the total flux incident on the crystal.

Other approaches to reduce to the heat load on the crystal include the use of mirrors as power filters [30], cryogenically cooled thin crystals, and asymmetrically cut crystals with adjustable asymmetry [13]. 
Table 5: Wiggler A crystal: Thermal and structural results. PHF is the peak heat flux on the crystal surface, $T_{\max }$ is the maximum temperature on the crystal surface, $\Delta \mathrm{T}_{\max }$ is the maximum temperature rise above the coolant temperature $\left(50{ }^{\circ} \mathrm{C}\right)$. The $\mathrm{Si}(111)$ Darwin width is given for comparison.

\begin{tabular}{|c|c|c|c|c|c|c|}
\hline $\begin{array}{c}\text { Energy } \\
{[\mathrm{keV}]}\end{array}$ & $\begin{array}{c}\theta_{\mathrm{Bragg}} \\
{[\mathrm{deg} .]}\end{array}$ & $\begin{array}{c}\mathrm{PHF} \\
{\left[\mathrm{W} / \mathrm{mm}^{2}\right]}\end{array}$ & $\begin{array}{c}\mathrm{T}_{\max } \\
{\left[{ }^{\circ} \mathrm{C}\right]}\end{array}$ & $\begin{array}{c}\Delta T_{\max } \\
{\left[{ }^{\circ} \mathrm{C}\right]}\end{array}$ & $\begin{array}{c}\text { Maximum } \\
\text { slope } \\
{[\mu \mathrm{rad}]}\end{array}$ & $\begin{array}{c}\text { Darwin } \\
\text { width } \\
{[\mu \mathrm{rad}]}\end{array}$ \\
\hline 8 & 14.3 & 18.5 & 108.0 & 58.0 & 54.0 & 33.9 \\
\hline 16 & 7.1 & 9.27 & 88.0 & 38.0 & 18.0 & 16.6 \\
\hline 24 & 4.7 & 6.14 & 80.0 & 30.0 & 14.0 & 11.0 \\
\hline 56.65 & 2.0 & 2.61 & 65.8 & 15.8 & 12.0 & 4.7 \\
\hline
\end{tabular}


Table 6: Summary of scenarios for $10 \mathrm{keV}$ photons. $\mathrm{E}$ is the photons energy, $\mathrm{K}$ is the deflection parameter, Ec is the critical energy, Pd is the peak heat flux on the crystal surface. The Darwin width is for Si(111) reflection. Note that all calculations include the $0.600-\mathrm{mm}$-thick graphite filters and the 0.500 -mm-thick Be, windows before the monochromator location, and that maximum slope errors are based on the results of the FEA for the 2.1-cm gap case.

\begin{tabular}{|c|c|c|c|c|c|c|c|c|c|}
\hline $\begin{array}{c}\mathrm{E} \\
{[\mathrm{keV}]}\end{array}$ & Scenario & $\begin{array}{c}\text { Gap size } \\
{[\mathrm{cm}]}\end{array}$ & $\mathrm{K}$ & $\begin{array}{c}\text { Ec } \\
{[\mathrm{Kev}]}\end{array}$ & $\begin{array}{c}\text { Fraction } \\
\text { of the } \\
\text { Incident } \\
10-\mathrm{keV} \\
\text { Photons }\end{array}$ & $\begin{array}{c}\text { Incident } \\
\text { Power } \\
{[\mathrm{kW}]}\end{array}$ & $\begin{array}{c}\text { Pd } \\
{\left[\mathrm{W} / \mathrm{mm}^{2}\right]}\end{array}$ & $\begin{array}{c}\text { Maximum } \\
\text { Slope } \\
{[\mu \mathrm{rad}]}\end{array}$ & $\begin{array}{c}\text { Darwin } \\
\text { Width } \\
{[\mu \mathrm{rad}]}\end{array}$ \\
\hline \multirow{2}{*}{10} & $\begin{array}{c}\text { gap } \\
\text { opening }\end{array}$ & 4.75 & 2.44 & 10.0 & $25 \%$ & 0.35 & 3.6 & 12.5 & \multirow{2}{*}{27} \\
\cline { 2 - 9 } & $\begin{array}{c}\text { Filters: } \\
18 \text {-mm C }\end{array}$ & 2.1 & 7.94 & 32.6 & $0.011 \%$ & 2.0 & 6.4 & 14.0 & \\
\cline { 2 - 10 } & No filters & 2.1 & 7.94 & 32.6 & $100 \%$ & 5.8 & 14.8 & 38.0 & \\
\hline
\end{tabular}




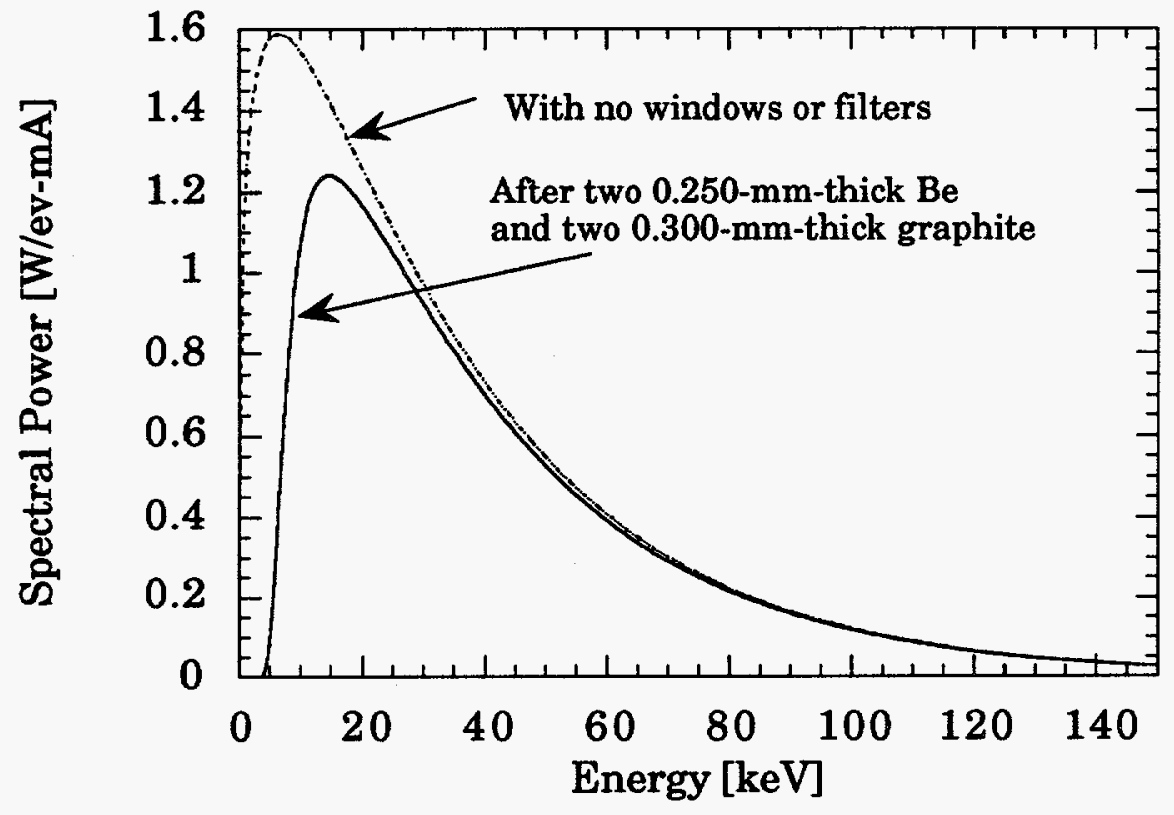

Fig. IV.1: Wiggler A $[\lambda=8.5 \mathrm{~cm}]$ spectral power with and without beryllium windows and graphite filters. The plots are for a $2.1-\mathrm{cm}$ magnetic gap case, a ring energy of $7 \mathrm{GeV}$, and a current of $100 \mathrm{~mA}$. 
(a)

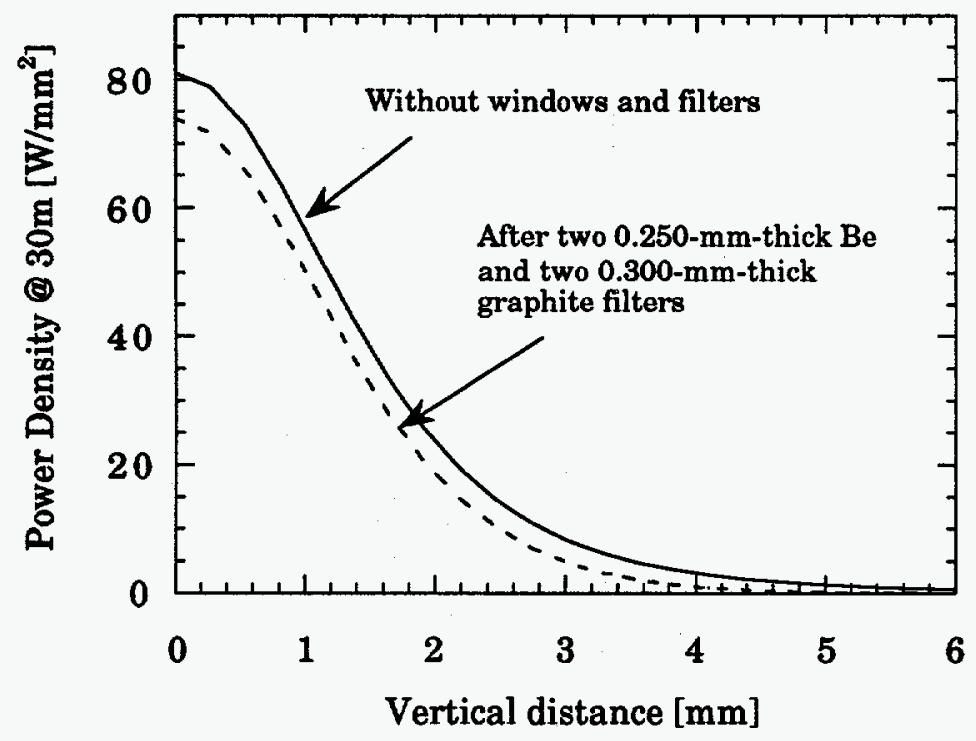

(b)

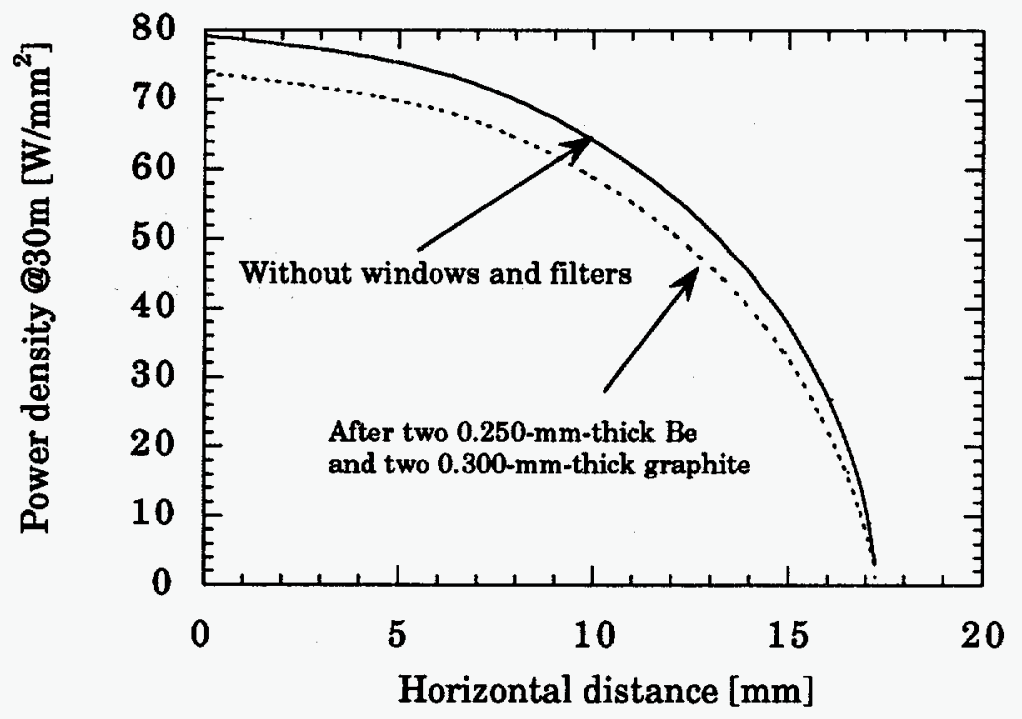

Fig. IV.2: Wiggler $A[\lambda=8.5 \mathrm{~cm}]$ (a) vertical and (b) horizontal spatial power density profiles at $30 \mathrm{~m}$ from source, for $7 \mathrm{GeV}-100 \mathrm{~mA}$ operation. 


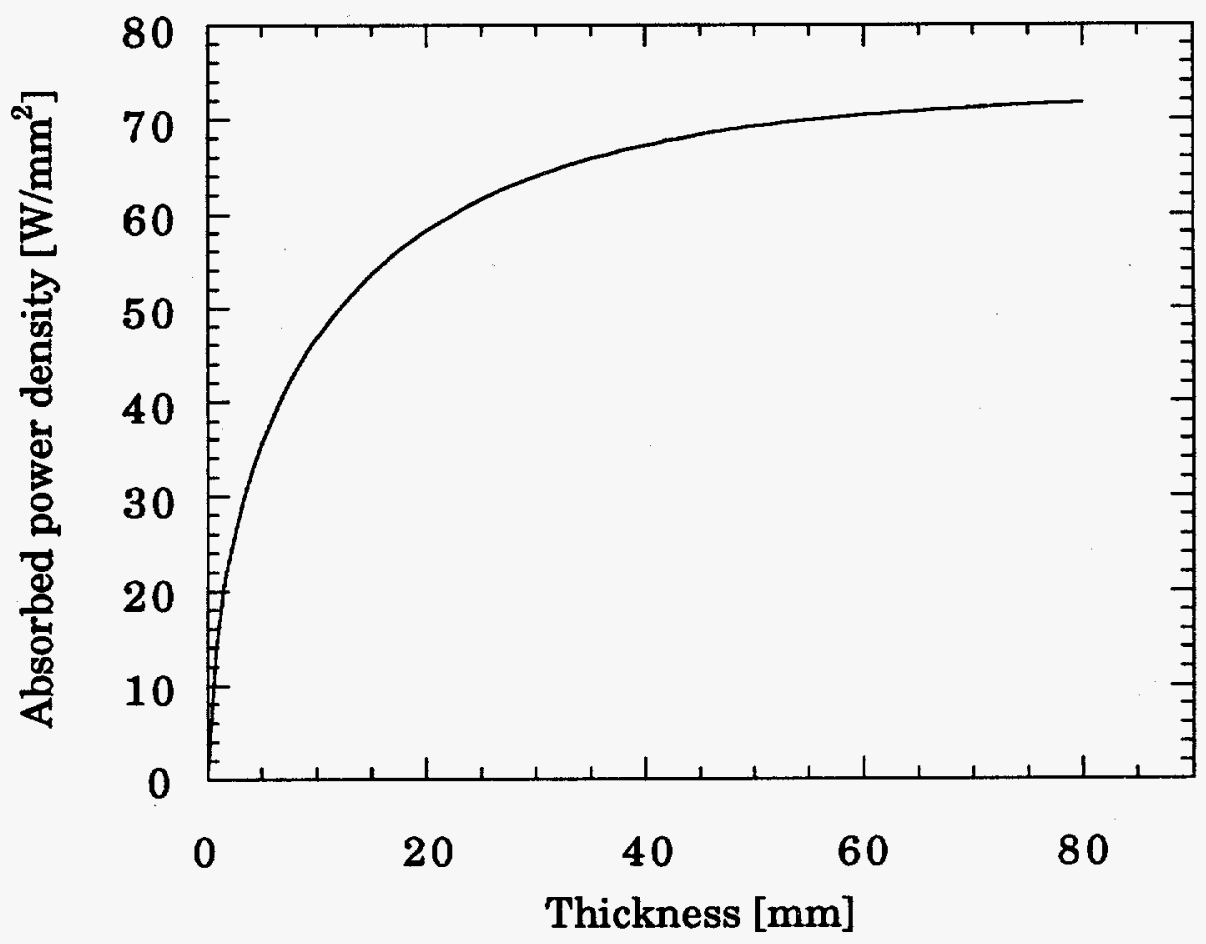

Fig. IV.3: Absorbed power density, as function of thickness, at $30 \mathrm{~m}$ from source, by a silicon crystal subjected to APS Wiggler A (2.1-cm gap, $K=7.94$ ) operating at $7 \mathrm{GeV}$ and $100 \mathrm{~mA}$. The calculation was performed by dividing the crystal into several layer and calculating the difference between the incident and the absorbed power density for each layer. 


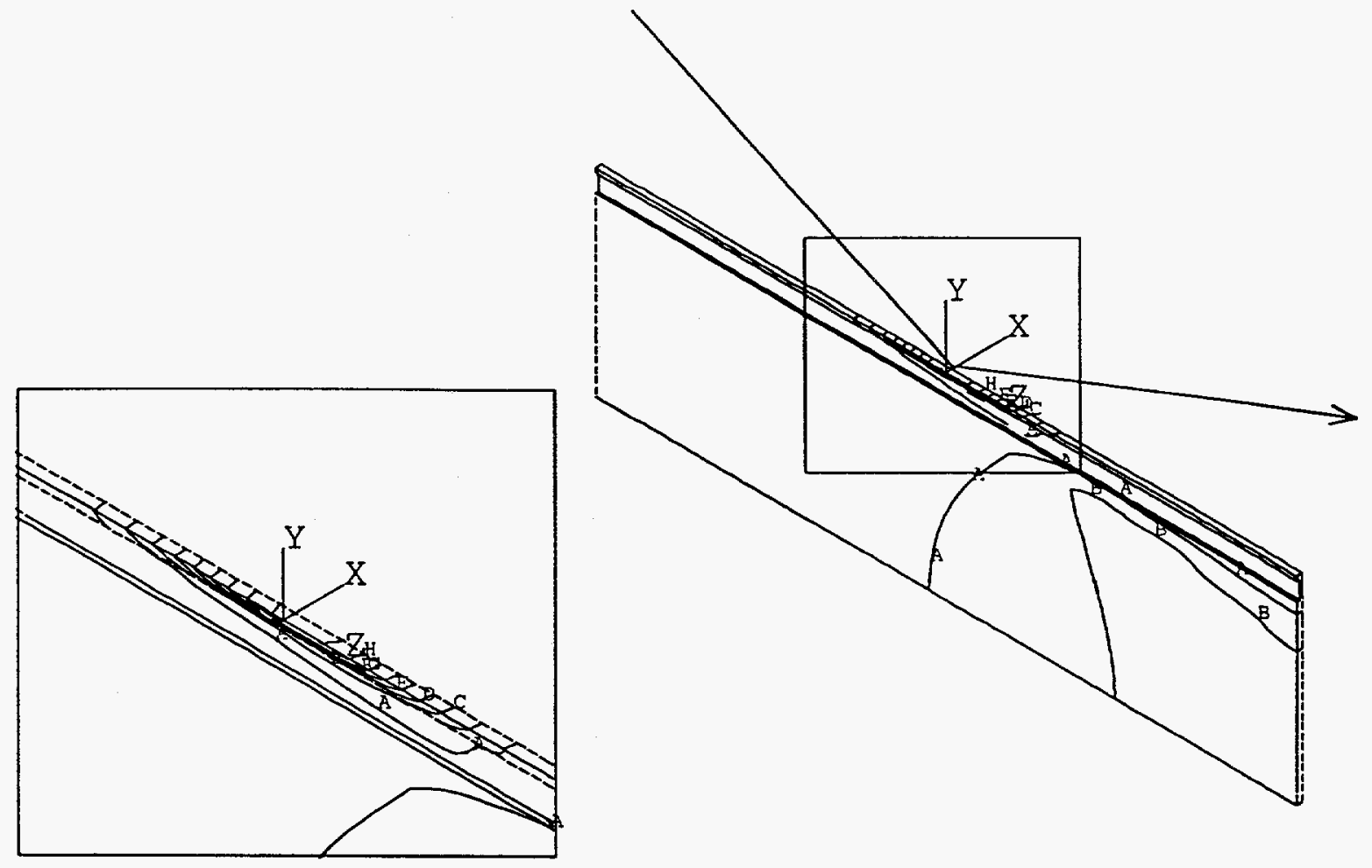

$$
\begin{array}{ll}
A & =53.344 \\
B & =60.032 \\
C & =66.72 \\
D & =73.408 \\
E & =80.096 \\
F & =86.784 \\
G & =93.472 \\
H & =100.16 \\
\text { I } & =106.848
\end{array}
$$

Fig. IV.4: Temperature profile, in ${ }^{\circ} \mathrm{C}$, within a $\mathrm{Si}(111)$ crystal oriented to diffract $8-\mathrm{keV}$ photons. The plots show the simulated channel-cell, which is located at the crystal center line, along the beam direction. 


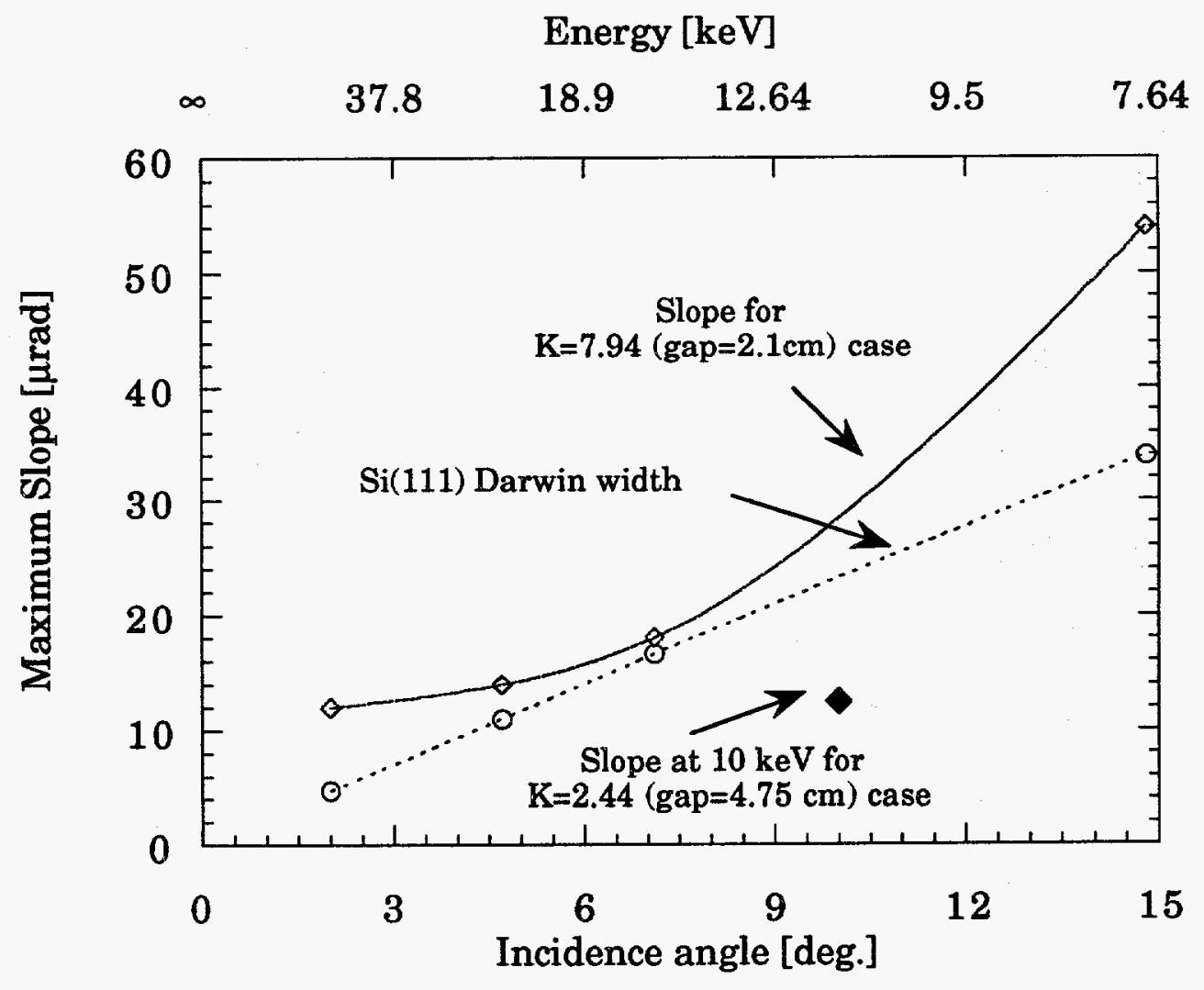

Fig. IV.5: Calculated total distortion as a function of incidence angle. For reference, the corresponding energy (top axis) and the Darwin width are also plotted for $\mathrm{Si}(111)$ reflection. 


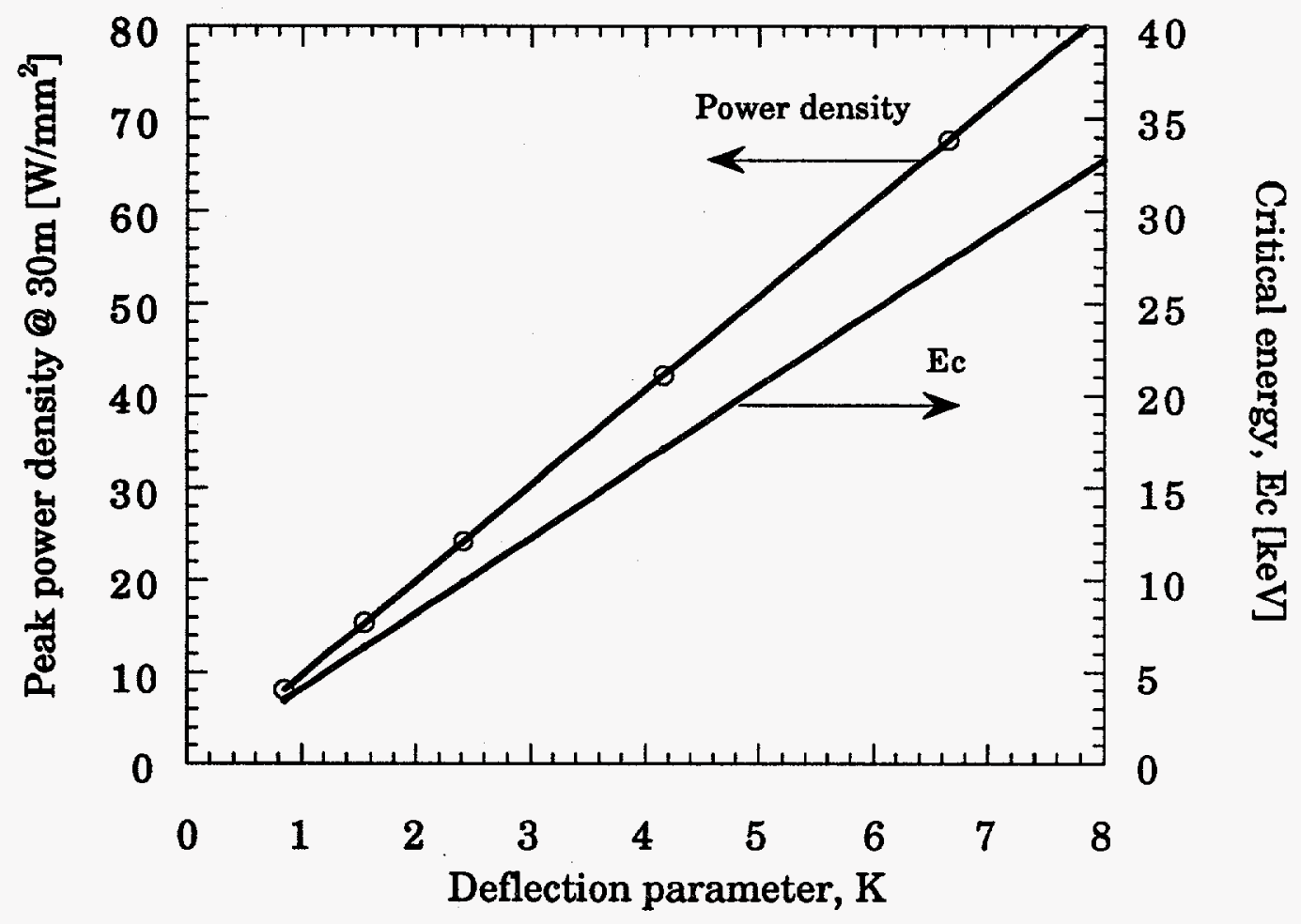

Fig. IV.6: Peak heat flux at $30 \mathrm{~m}$ from source and the critical energy of Wiggler $A[\lambda=8.5 \mathrm{~cm}]$ as a function of the deflection parameter for $7 \mathrm{GeV}-100$ $\mathrm{mA}$ operation (data taken from Ref. 28). 


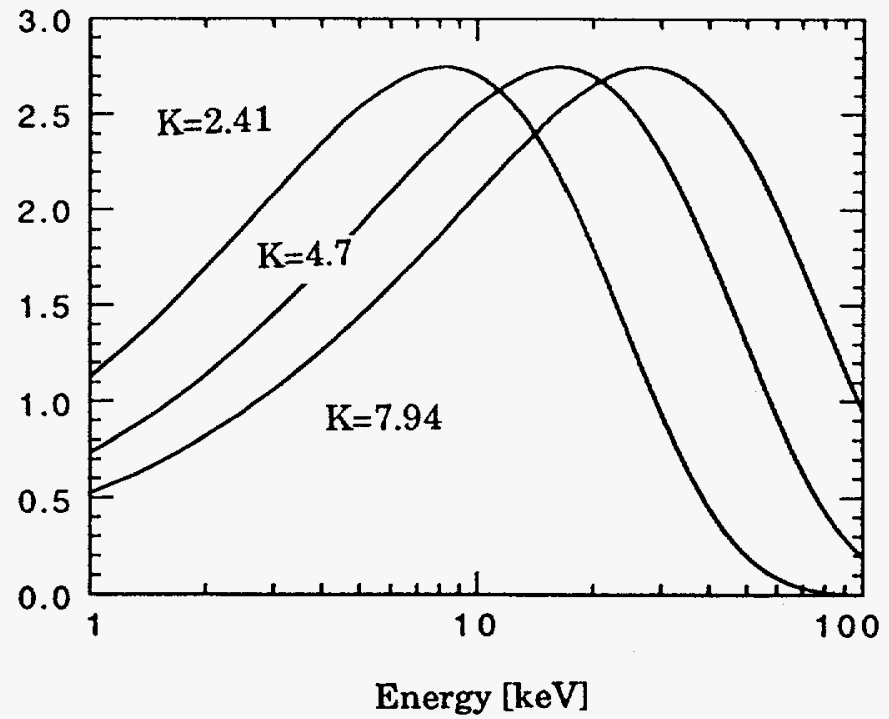

Fig. IV.7: On-axis brilliance spectra (plotted in log-log scale) for Wiggler A operating at different gap openings [from Ref. 28]. The plots are for $7 \mathrm{GeV}$ $100 \mathrm{~mA}$ operation.

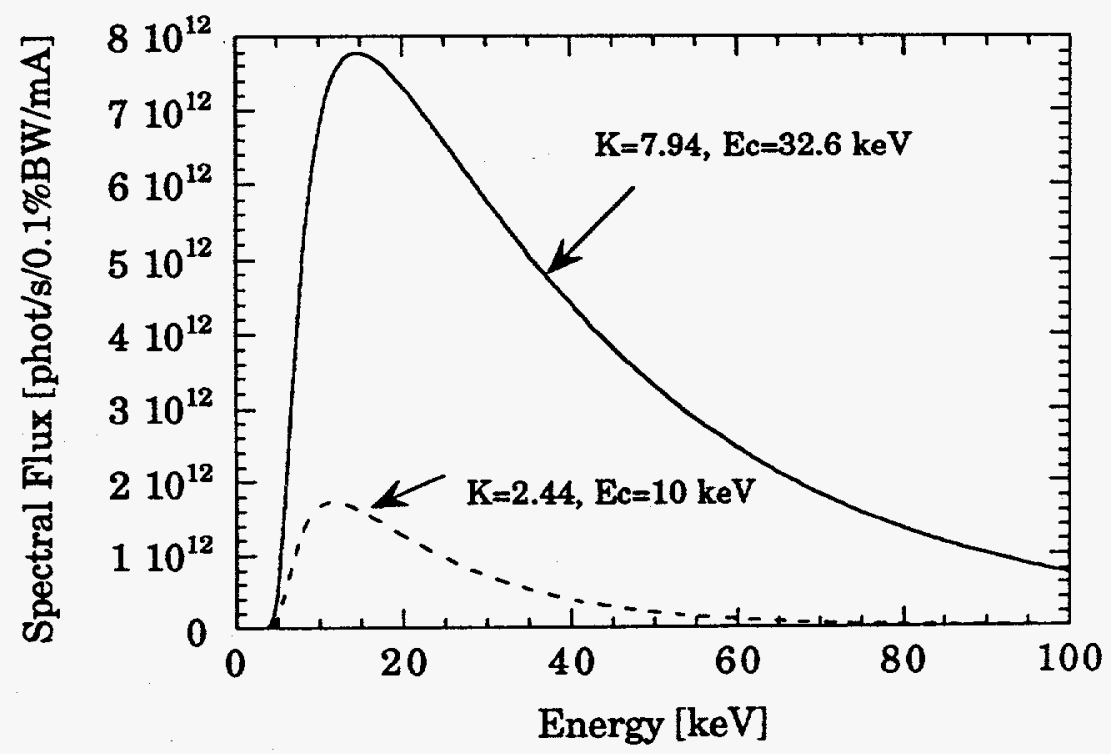

Fig. IV.8: Flux spectra for Wiggler $A$ operating at $\mathrm{K}=2.44(\mathrm{Ec}=10 \mathrm{keV})$, and $\mathrm{K}=7.94$ (closed gap). The plots are for $7 \mathrm{GeV}-100 \mathrm{~mA}$ operation. 


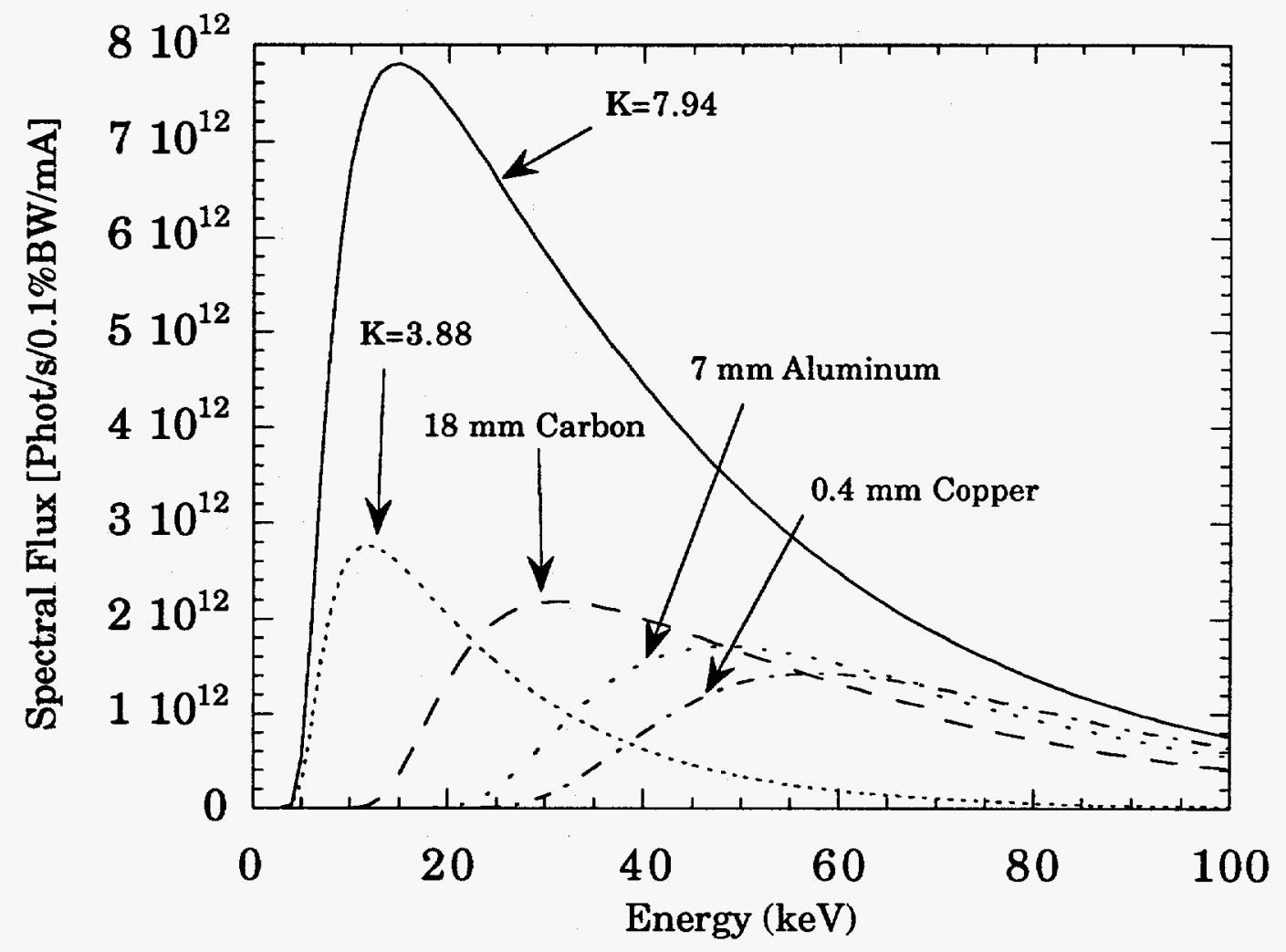

Fig. IV.9: Comparison of flux incident on the crystal between the case of a magnetic gap of $2.1 \mathrm{~cm}(\mathrm{~K}=7.94, \mathrm{Ec}=32.6 \mathrm{keV})$ with a variety of filters and the case of $3.7-\mathrm{cm}$ magnetic gap $(\mathrm{K}=3.88, \mathrm{Ec}=15.95)$ with no filters. Flux calculations were performed with PHOTON2. This comparison is for a $\mathrm{Si}(111)$ crystal set to $11.4^{\circ}$ Bragg angle (10 keV). The filters and gap opening are set so that, based on FEA results, the total distortion on the crystal surface is half of the Darwin width of the reflection. The advantage of opening the Wiggler A gap is clear in this case. At 3.7-cm gap $(\mathrm{K}=3.88)$, the number of $10-\mathrm{keV}$ photons is about $40 \%$ that produced by the wiggler at 2.1cm gap (K=7.94). 


\section{The Inclined Crystal for Undulator A}

\section{A. Properties of the source}

1. Undulator A parameters

The APS Undulator A parameters are listed in Table 7 [31]:

Table 7. Undulator A Parameters.

\begin{tabular}{|l|c|}
\hline \multicolumn{1}{|c|}{ Parameter } & Value \\
\hline Undulator Period, $\lambda[\mathrm{cm}]$ & 3.3 \\
\hline Number of Periods, $\mathrm{N}$ & 72 \\
\hline Device Length, $\mathrm{L}[\mathrm{m}]$ & 2.4 \\
\hline Gap $[\mathrm{mm}]$ & 12.87 \\
\hline Deflection Parameter, $\mathrm{K}_{\mathrm{eff}}(\mathrm{Kmax})$ & $2.17(2.19)$ \\
\hline Magnetic Field, $\left.\mathrm{B}_{\mathrm{eff}}[\mathrm{T}], \mathrm{B}_{\max }\right)$ & $0.704(0.7104)^{*}$ \\
\hline First Harmonic Energy $\mathrm{E}_{1}[\mathrm{keV}]$ & 4.2 \\
\hline Characteristic Energy, $\mathrm{E}_{\mathrm{c}}[\mathrm{kev}]$ & 23.5 \\
\hline Peak Power Density $\left[\mathrm{kW} / \mathrm{mrad}^{2}\right]$ & 135 \\
\hline Total Power $[\mathrm{kW}]$ & 3.8 \\
\hline
\end{tabular}

*Measured value.

2. Power, heat flux, and source spectra.

Simulations were performed for two different deflection parameters: $K=2.17$, corresponding to the first harmonic at $4.2 \mathrm{keV}$, and $\mathrm{K}=1.23$, corresponding to the first harmonic at $8 \mathrm{keV}$.

At a ring energy of $7 \mathrm{GeV}$ and a current of $100 \mathrm{~mA}$, the total power and the normal peak heat flux (including beam emittance effects) generated by Undulator $A$ at $30 \mathrm{~m}$ from the source are: 
For the first harmonic at $4.2 \mathrm{keV}$ :

Total power $=3.8 \mathrm{~kW}$

Peak heat flux $=140 \mathrm{~W} / \mathrm{mm}^{2}$

For the first harmonic at $8 \mathrm{keV}$ :

Total power $=1.18 \mathrm{~kW}$

Peak heat flux $=75 \mathrm{~W} / \mathrm{mm}^{2}$.

Because it may be necessary to operate the undulator beamline in a windowless mode, no filters or Be windows were included in this worst-case calculation. The vertical and horizontal spatial power density profiles, calculated using the URGENT code [32], are given in Fig. V.1. The Undulator A spectral power, calculated using the same computer code, is shown in Fig. V.2.

\section{B. Description and analyses of the crystal}

\section{Crystal geometry and cooling parameters}

For the inclined crystal (see Fig. V.3), the planes of diffraction make an angle $\beta$ with the crystal surface, thereby spreading the power density on the crystal surface by a factor of $1 /(\sin \theta \cos \beta)$, where $\theta$ is Bragg's angle. In the APS design [6], the inclination angle and energy range are originally chosen so that the power density on the crystal surface does not exceed about $5 \mathrm{~W} / \mathrm{mm}^{2}$ and the crystal is under $250 \mathrm{~mm}$ long [6]. The surface power density limit was chosen based on previous experimental and computer simulation results. The APS design calls for one set of $\mathrm{Si}(111)$ crystals with $85^{\circ}$ inclination to cover the energy range from 4 to $9 \mathrm{keV}$, while another set with $78^{\circ}$ inclination to cover the 8 to $20 \mathrm{keV}$ energy range. For further details on the concept and geometry of the inclined crystal refer to references [6-12].

Fig. V.4 depicts the geometry used for the FEA model. The crystal is cooled by flowing liquid gallium through rectangular channels. Similar to the Wiggler A crystal, the channels are $1 \mathrm{~mm}$ wide and $3 \mathrm{~mm}$ deep; the thickness of the fins is equal to $1 \mathrm{~mm}$, and that of crystal face plate is $0.7 \mathrm{~mm}$. The channels are oriented transverse to the crystal (see Fig. V.4).

The coolant flow rate was chosen to be $4 \mathrm{gpm}$, flowing in 50 channels, which corresponds to a fluid velocity of $1.68 \mathrm{~m} / \mathrm{s}$. The heat transfer coefficient, 
estimated using equations (1) and (2), is about $18 \mathrm{~W} / \mathrm{cm}^{2}-\mathrm{K}$. The coolant average temperature is set to $50^{\circ} \mathrm{C}$, and its temperature rise is estimated to be $6{ }^{\circ} \mathrm{C}$.

\section{Power load and boundary conditions}

Because of the high inclination angles with which we are dealing, the crystal intercepts the beam at a very shallow glancing angle. Therefore, we assume that the incident power is totally deposited on the crystal surface. The power density profiles calculated using the URGENT code are shown in Fig. V.1. To keep the sizes of the crystals reasonable, it has been assumed that slits could be used to let through only the central radiation cone. The slit opening at 30 $\mathrm{m}$ from the source is $3.6 \mathrm{~mm}$ in the horizontal direction and $1.8 \mathrm{~mm}$ in the vertical direction, which corresponds to $>4 \sigma$ of the central harmonic radiation cone. The total incident power is reduced to about 750 watts for $\mathrm{K}=2.17$ (the first harmonic at $4.2 \mathrm{keV}$ ), and to about 400 watts for $\mathrm{K}=1.23$ (the first harmonic at $8 \mathrm{keV}$ ). There has been concern, however, that the use of vertical slits introduces a sharp thermal gradient, thereby increasing the thermally induced slope, and this is also a question we sought to answer.

Here, the planes of diffraction are not parallel to the surface, and the overall structure is not symmetric. Therefore, the full crystal was modeled. The incident power is treated as absorbed on the surface in the finite element thermal analysis. The thermal distortions are calculated assuming that the crystal is fixed at the bottom face. This is a reasonable assumption when the crystal base is made relatively thick (several $\mathrm{cm}$ ).

\section{Temperature and distortion results}

As mentioned previously, simulations were performed for two different deflection parameters: $K=2.17$ and 1.23. For $K=2.17$, the inclination angle, $\beta$, is $85^{\circ}$, and for $\mathrm{K}=1.23$, it is $78^{\circ}$. For each case, calculations were performed with and without vertical slits, and in all cases the horizontal slit opening is kept at $3.6 \mathrm{~mm}$. The results of the analyses are summarized in Table 8. Fig. V.5 shows the temperature profile on the surface of a $78^{\circ}$-inclined crystal set to diffract $8-\mathrm{keV}$ photons. The horizontal silt opening is set to $3.6 \mathrm{~mm}$, while the vertical slits are left wide open. Figs. V.6 and 7 show the variation of 
displacement and the slope in the direction of the reciprocal lattice vector for the two cases. A comparison is made between the case where vertical slits are used and the case with no vertical slits.

Figs. V.6 and 7 reveal that, for an inclined geometry, the thermally induced slope error under the beam footprint has a constant sign. The peak slope error for the $4.2-\mathrm{keV}$ case (and with $1.8-\mathrm{mm}$ vertical slits), for example, is about $34 \mu \mathrm{rad}$. The peak slope error represents the maximum deviation from Bragg's angle. The effective thermally induced slope error, which contributes to the broadening of the rocking curve, is the difference between the peak slope and the slope at the edge of beam. Its value for the $4.2-\mathrm{keV}$ case with $1.8-\mathrm{mm}$ vertical slits is about $21 \mu \mathrm{rad}$. This is to be compared with the Darwin width of $71 \mu \mathrm{rad}$.

For the $78^{\circ}$-inclined $\mathrm{Si}(111)$ crystal set to diffract $8-\mathrm{keV}$ photons, the maximum effective slope error is only about $7 \mu \mathrm{rad}$ (for 1.8 -mm vertical slits). This is to be compared with the Darwin width of $33.9 \mu \mathrm{rad}$.

Regarding the effect of vertical slits, the FEA results indicate that the thermally induced slope error increases when a $1.8-\mathrm{mm}$ vertical slit opening is used. The effect is worse for the $4.2-\mathrm{keV}$ case, in which the use of slits almost doubles the effective slope error. Thus, vertical slits should be left open to minimize the slope errors. This is can be done without affecting the crystal size because the length of the crystal depends mostly on the inclination angle and the horizontal size of the beam.

\section{Conclusion}

The above simulations predict that a gallium-cooled inclined crystal will perform reasonably well when subjected to the APS Undulator A beam. For the worst-case scenario, $4.2-\mathrm{keV}$ photons, $85^{\circ}$ inclination angle, the effective thermal distortion (for the slitted beam) is only $21 \mu \mathrm{rad}$. This is to be compared with the Darwin width of $71 \mu \mathrm{rad}$ for this reflection. For the case of $8-\mathrm{keV}$ photons with $78^{\circ}$ inclination, the effective thermally induced slope error for the slitted-beam case is about $7 \mu \mathrm{rad}$ or $20 \%$ of the intrinsic Darwin width. 
Overall, the results are encouraging. Even for the worst-case studied (4.2 $\mathrm{keV}$ ), the slope error is only about $30 \%$ of the Darwin width. For the 8-keV case presented above, further improvement is certainly possible by going to inclination angles higher than $78^{\circ}$. We chose $78^{\circ}$ because we wanted to keep the surface power densities to less than about $5 \mathrm{~W} / \mathrm{mm}^{2}$ and to have the crystal operate within the 8 to $20 \mathrm{keV}$ range without the crystal size exceeding $250 \mathrm{~mm}$. It is up to the individual crystal designer to balance allowable distortions, energy ranges, inclination angles, and crystal sizes to their needs. In general, we do not recommend inclination angles greater than $85^{\circ}$ due to the difficulty in alignment. 
Table 8: Temperature and distortion in the direction of the reciprocal lattice vector of an inclined $\mathrm{Si}(111)$ crystal subjected to an APS undulator A beam at $7 \mathrm{GeV}-100 \mathrm{~mA}$ operation. $E_{1}$ is the energy of the first harmonic; $\beta$ is the inclination angle; PHF is the peak heat flux on the crystal surface; $T_{\max }$ is the maximum temperature on the crystal surface; $\mathrm{T}_{\mathrm{bfp}}$ is the temperature at the bottom of the face plate; $\Delta \mathrm{T}_{\mathrm{c}}$ is the temperature drop across the crystal face plate; $U_{\max }$ is the maximum displacement. The slit opening is 3.6 $\mathrm{mm} \times 1.8 \mathrm{~mm}$ at $30 \mathrm{~m}$.

\begin{tabular}{|c|c|c|c|c|c|c|c|c|c|c|c|}
\hline $\begin{array}{c}\mathrm{E}_{1} \\
{[\mathrm{keV}]}\end{array}$ & $\begin{array}{c}\beta \\
\text { (incl. } \\
\text { angle) }\end{array}$ & $\theta_{\text {Bragg }}$ & $\begin{array}{c}\text { PHF } \\
{\left[\mathrm{W} / \mathrm{mm}^{2}\right]}\end{array}$ & $\begin{array}{c}\text { Vertical } \\
\text { slits config. }\end{array}$ & $\begin{array}{c}\mathrm{T}_{\max } \\
{\left[{ }^{\circ} \mathrm{C}\right]}\end{array}$ & $\begin{array}{l}\mathrm{T}_{\mathrm{bfp}} \\
{\left[{ }^{\circ} \mathrm{C}\right]}\end{array}$ & $\begin{array}{c}\Delta \mathrm{T}_{\mathrm{FP}} \\
{\left[{ }^{\circ} \mathrm{C}\right]}\end{array}$ & $\begin{array}{l}U_{\max } \\
{[\mu \mathrm{m}]}\end{array}$ & $\begin{array}{c}\text { Peak } \\
\text { slope }_{\max } \\
{[\mu \mathrm{rad}]}\end{array}$ & $\begin{array}{c}\text { Effective } \\
\text { slope* }^{*} \\
\text { [urad] }\end{array}$ & $\begin{array}{l}\text { Darwin } \\
\text { Width } \\
\text { [urad] }\end{array}$ \\
\hline 4.2 & $85^{\circ}$ & $28.06^{\circ}$ & 5.7 & with slits & 93.2 & 66.4 & 26.8 & 0.064 & 33.8 & 21.0 & 71.0 \\
\hline 8 & $78^{\circ}$ & $14.30^{\circ}$ & 3.8 & no slits & 84.8 & 64.5 & 20.3 & 0.073 & 12.2 & 5.0 & 33.9 \\
\hline
\end{tabular}

* The effective slope error is calculated for the central radiation cone and is defined as the difference between the peak slope and the slope at the edge of the beam. 
(a)

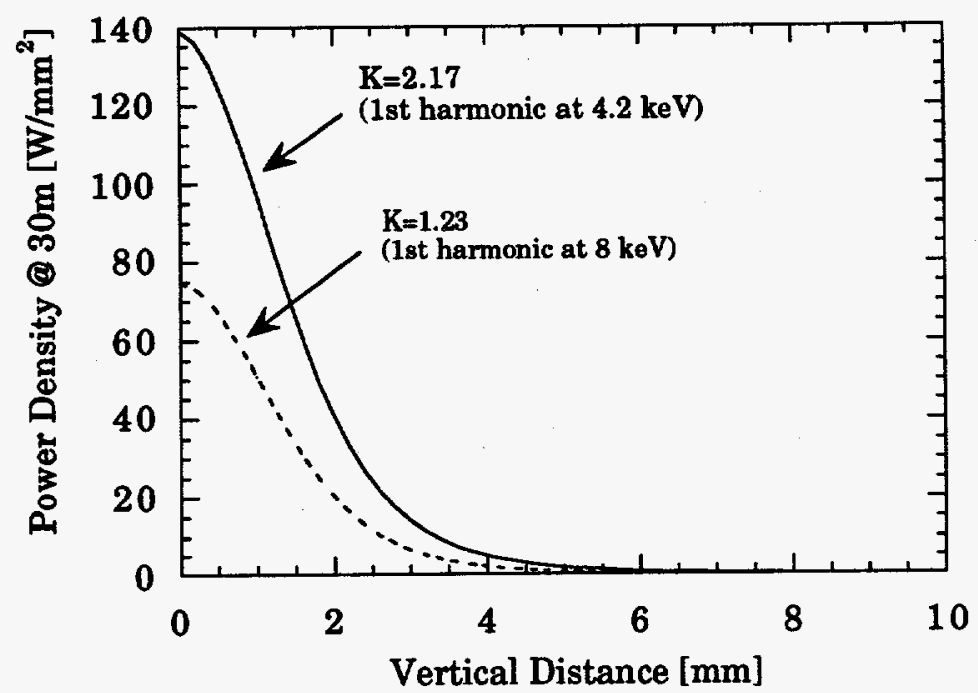

(b)

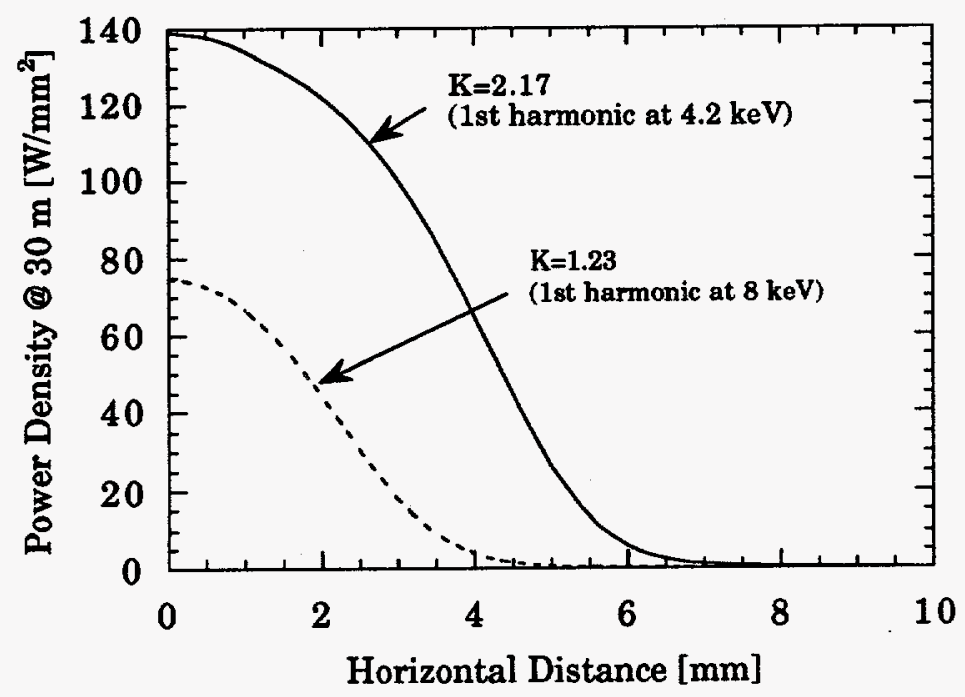

Fig. V.1: The APS Undulator A (a) vertical and (b) horizontal power density profiles at $30 \mathrm{~m}$ from source for $\mathrm{K}=2.17$ and 1.23 . The profiles are for Undultor $A$ beam at a ring energy of $7 \mathrm{GeV}$ and a current of $100 \mathrm{~mA}$. 


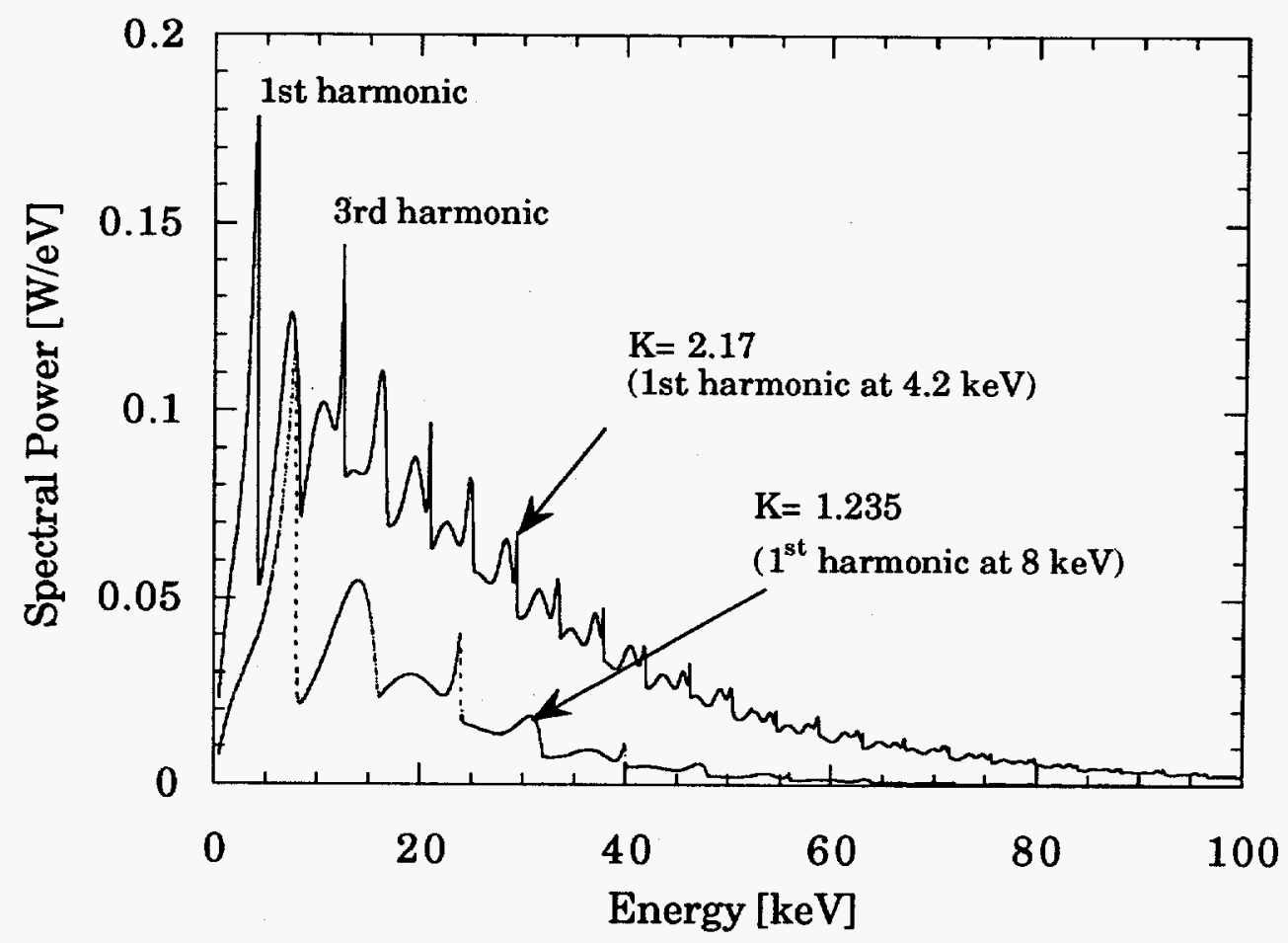

Fig. V.2: The APS Undulator A power spectra for $\mathrm{K}=1.235(\mathrm{E}=8 \mathrm{keV})$ and for $\mathrm{K}=2.17(\mathrm{E}=4.2 \mathrm{keV})$. The plots are for a ring energy of $7 \mathrm{GeV}$ and a current of $100 \mathrm{~mA}$. The total powers are $1.18 \mathrm{~kW}$ for $\mathrm{K}=1.235$ and $3.65 \mathrm{~kW}$ for $\mathrm{K}=2.17$. 


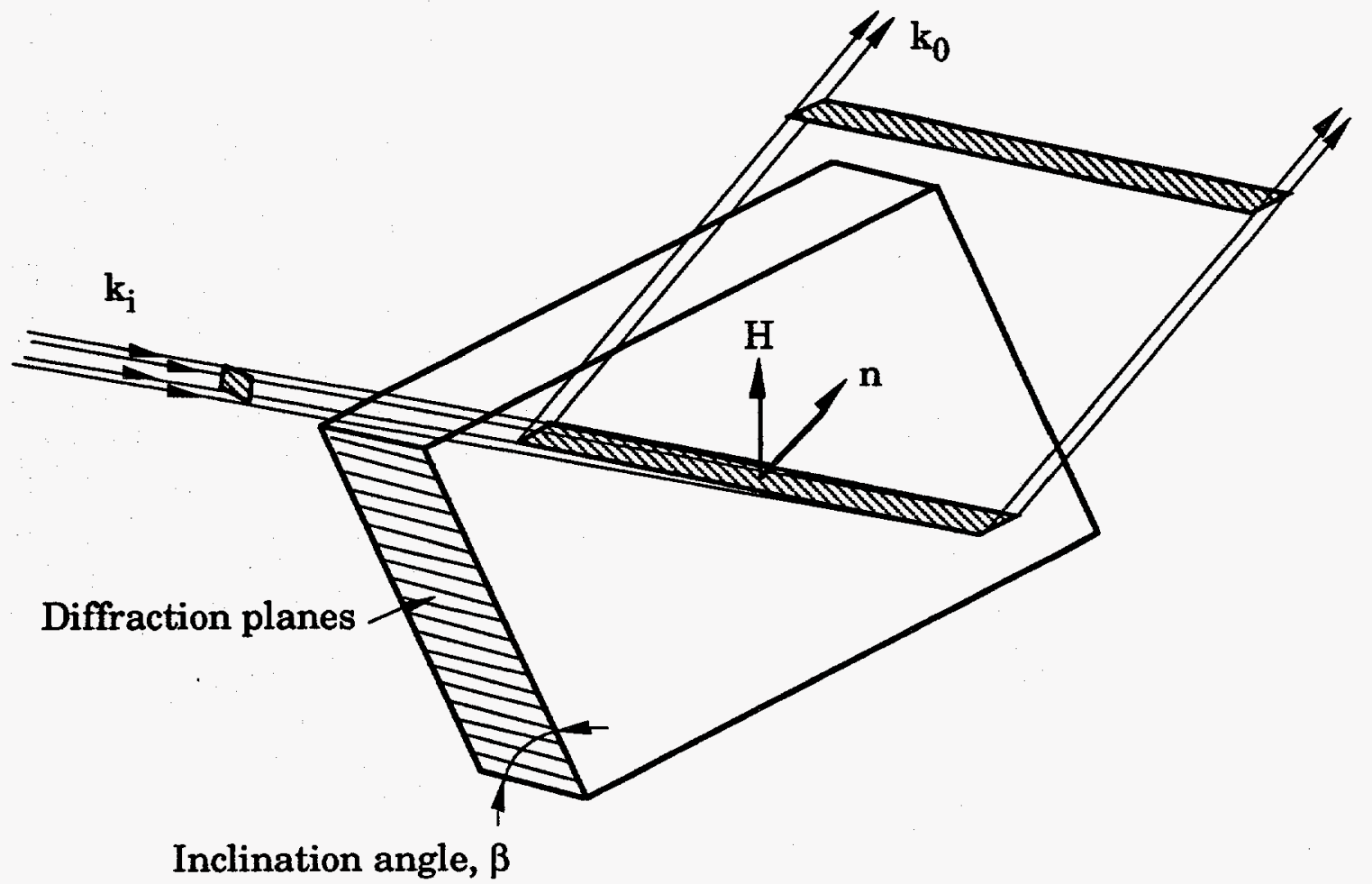

Incident beam

Footprint on the crystal surface
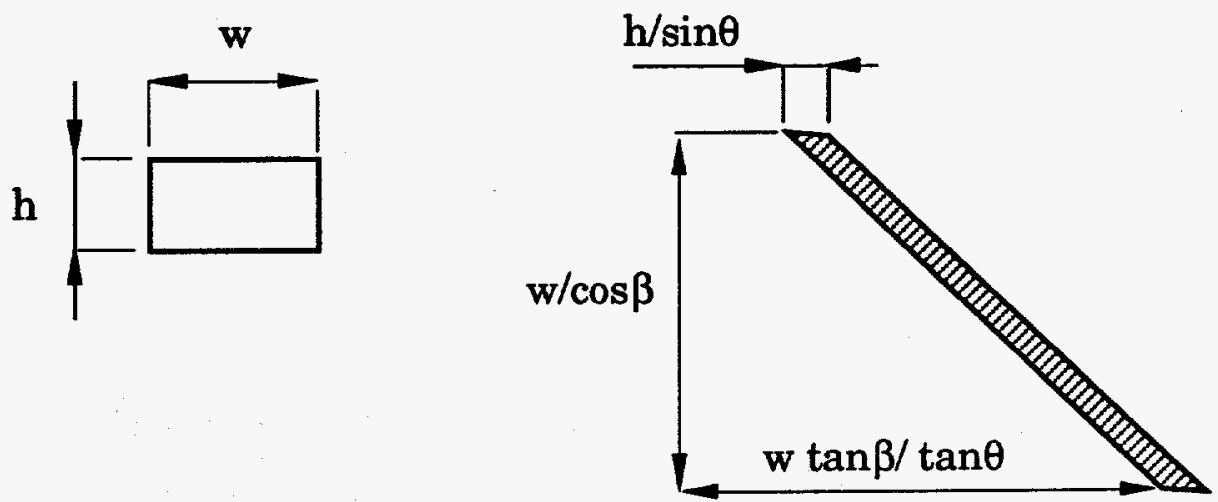

Fig. V.3: The inclined crystal geometry. 


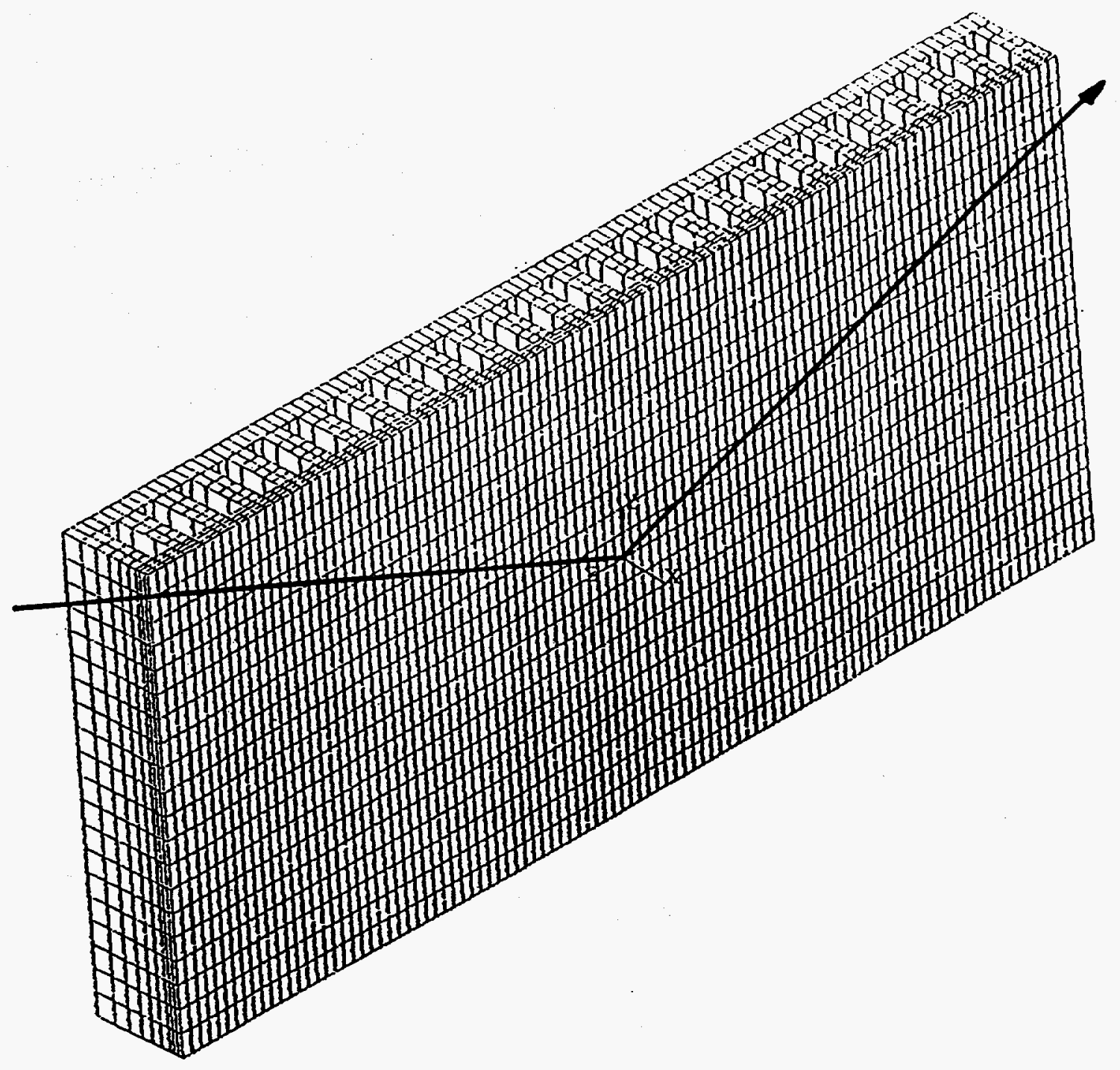

Fig. V.4: The geometry chosen to model the inclined crystal. In this case the channels are oriented along the width of the crystal. They are $1 \mathrm{~mm}$ wide and $3 \mathrm{~mm}$ deep. The thickness of fins is $1 \mathrm{~mm}$ each, and that of the face plate is $0.7 \mathrm{~mm}$. 


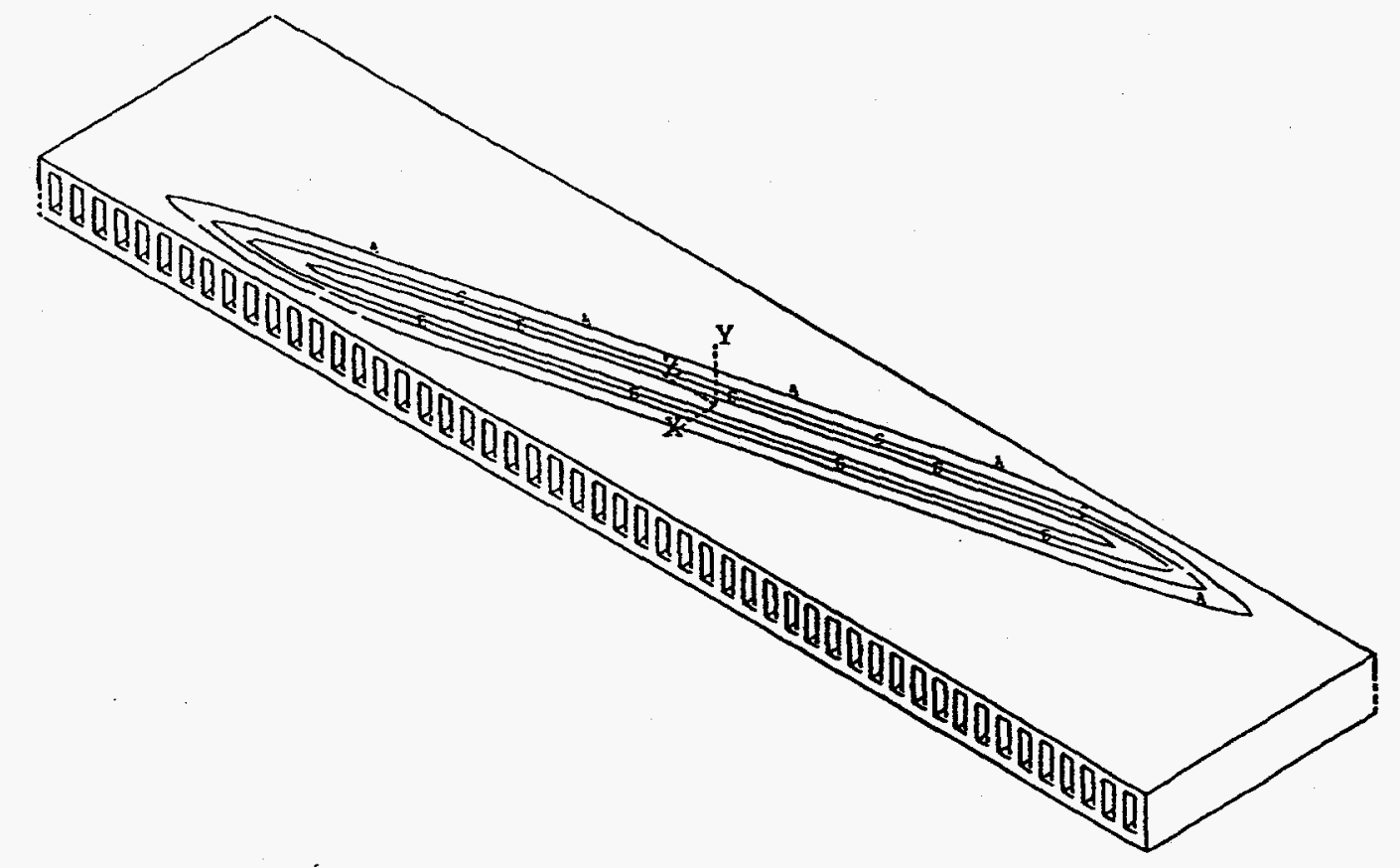

ANSYS $5.0 \mathrm{~A}$

AUG $17 \quad 1994$

$16: 18: 18$

PLOT NO. 1

NODAL SOLUTION

STEP $=1$

SUB $=4$

TIME $=1$

TEMP

TEPC $=0.957086$

SMN $=50$

SMX $=84.784$

$\mathrm{A} \quad=54.348$

$B=63.044$

C $=71.74$

D $\quad=80.436$

Fig. V.5: Temperature profile on the surface of a $78^{\circ}$-inclined crystal set to diffract $8-\mathrm{keV}$ photons from Undulator $A$ beam at $K=1.235$. The horizontal slit opening was set to $3.6 \mathrm{~mm}$, while the vertical slits were left wide open. SMX and SMN are the maximum and the minimum temperatures, respectively. 


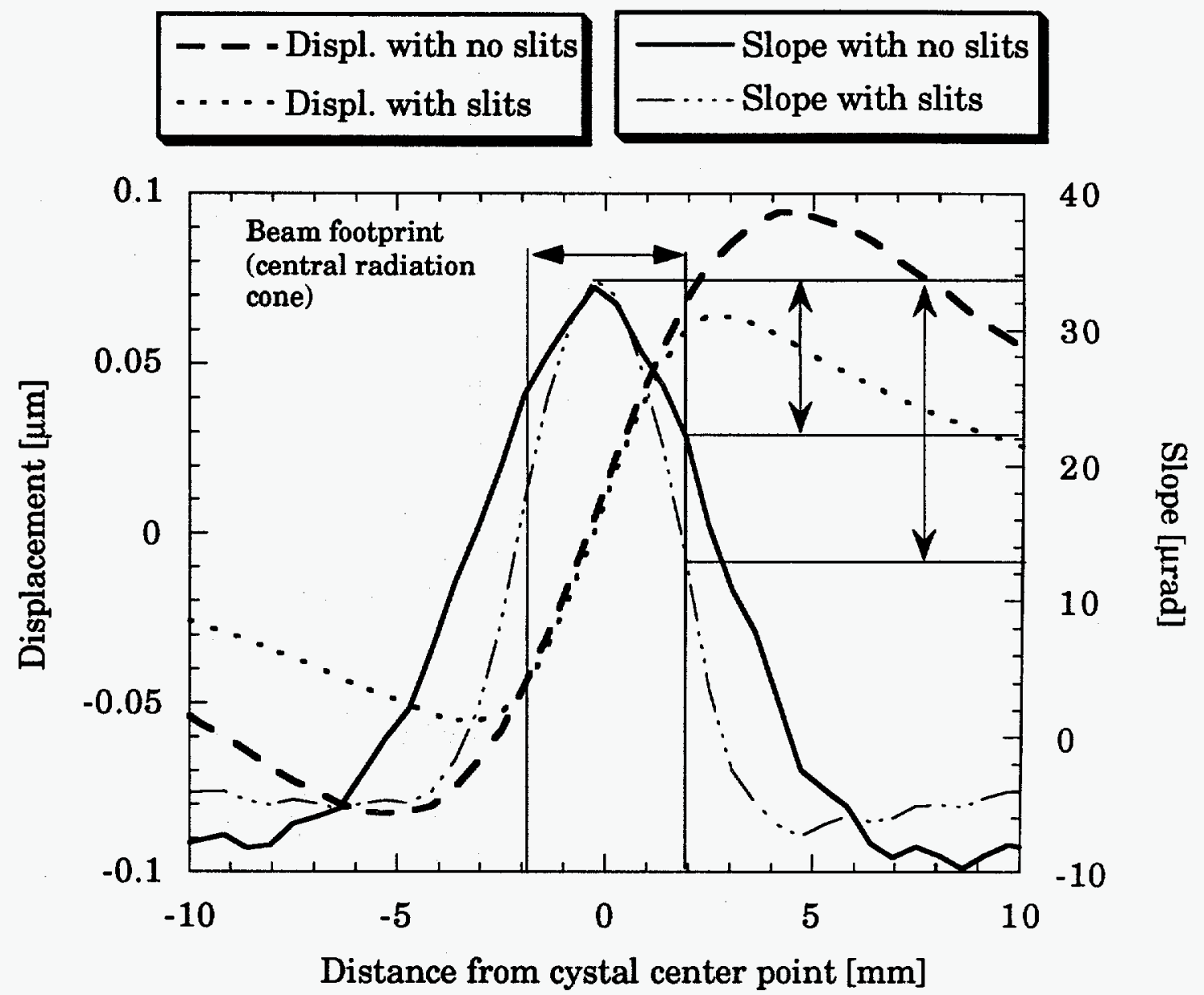

Fig. V.6: The inclined crystal: Displacement and thermally induced slope along the scattering plane for an $85^{\circ}$ inclined $\mathrm{Si}(111)$ crystal set to diffract the first harmonic at $4.2 \mathrm{keV}$; comparison is made between the case with vertical slits (with $1.8 \mathrm{~mm}$ opening) and the case with no vertical slits; the horizontal slits are kept at $3.6 \mathrm{~mm}$ in all cases. The crystal and the slits are assumed to be located at $30 \mathrm{~m}$ from source. This figure also indicates the beam footprint $(4 \times \sigma$ of the central radiation cone/sin $\theta)$ and the differential slopes. 
- - - Displacement with no slits

- . . - Displacement with slits
- Slope with no slits

Slope with no slits

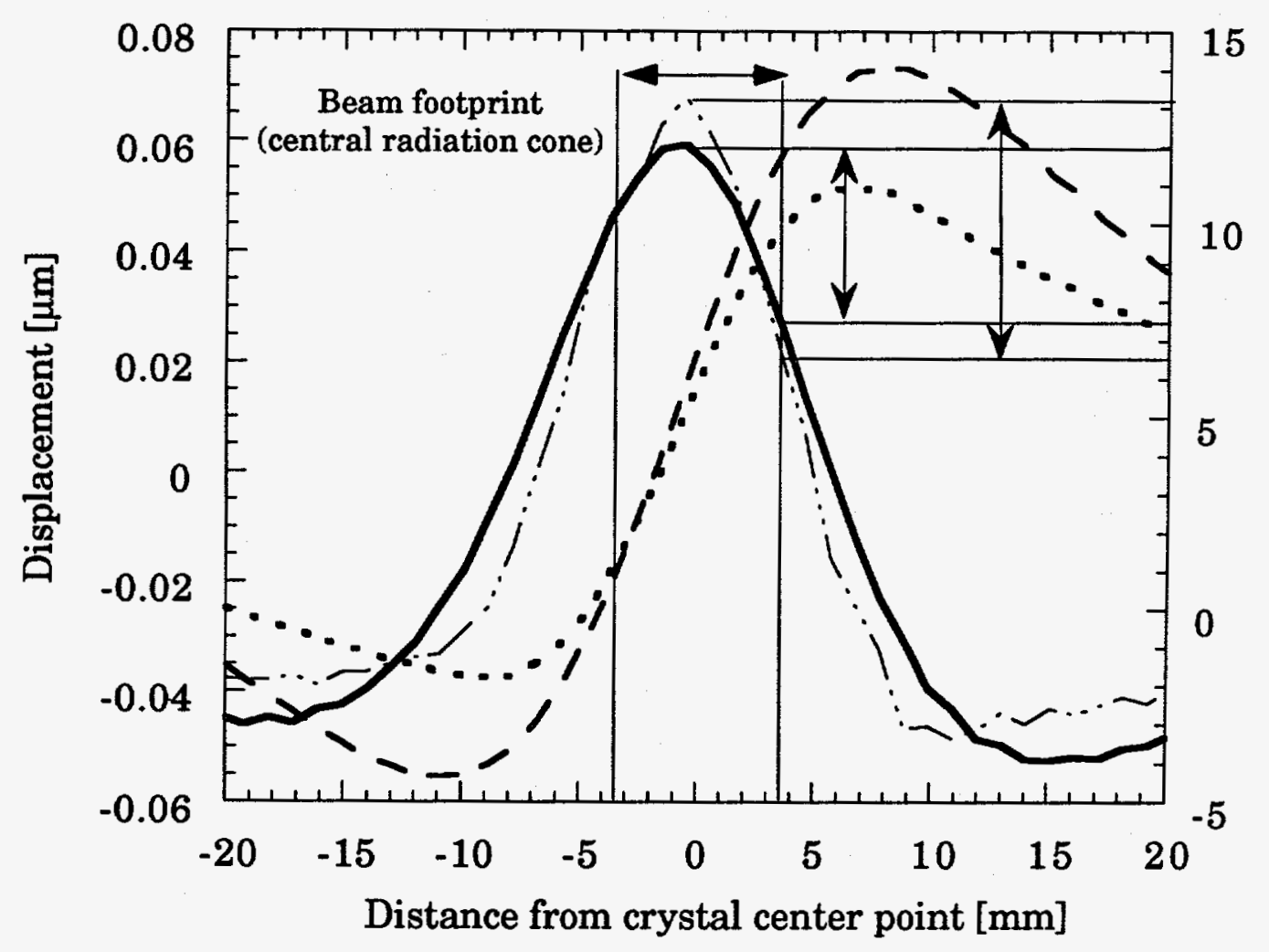

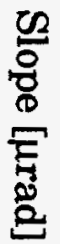

Fig. V.7: The inclined crystal: Displacement and thermally induced slope along the scattering plane for an $78^{\circ}$ inclined $\mathrm{Si}(111)$ crystal set to diffract the first harmonic at 8-keV; comparison is made between the case with vertical slits (with $1.8 \mathrm{~mm}$ opening) and the case with no vertical slits; the horizontal slits are kept at $3.6 \mathrm{~mm}$ in all cases. The crystal and the slits are assumed to be located at $30 \mathrm{~m}$ from source. This figure also indicates the beam footprint ( $4 \times \sigma$ of the central radiation cone/sin $\theta$ ) and the differential slopes. 


\section{Experimental Results}

This section summarizes our experimental results from various high-heatload tests at CHESS and BNL. Fig. VI.1. shows the results of our first inclined crystal run at CHESS in September 1991 [33] using the CHESS/ANL undulator. The crystals had slots of about $1 \mathrm{~mm}$ wide and $3 \mathrm{~mm}$ deep, separated by about $1 \mathrm{~mm}$. The bottom of the slots were about $0.8 \mathrm{~mm}$ from the surface of the crystal. Liquid gallium was used as a coolant. Details may be found in the reference. In the setup, the maximum normal incidence power density at the crystal at $100 \mathrm{~mA}$ ring current was about $32 \mathrm{~W} / \mathrm{mm}^{2}$. As can be seen from the figure, in the case of the flat crystal, the point at which a $10 \%$ loss in intensity occurs is at about $30 \mathrm{~mA}$ ring current. At $23.3^{\circ} \mathrm{Bragg}$ angle (5 keV Si(111)), this corresponds to a surface power density of about 3.8 $\mathrm{W} / \mathrm{mm}^{2}$. In the inclined crystal case, with a spreading by a factor of 3 over the flat crystals, the $10 \%$ loss point moved correspondingly upwards in current by nearly the same factor to $80 \mathrm{~mA}$.

Another test of the inclined geometry was performed at the X-25 focused beamline at the NSLS in September 1991 [34]. In this case, the normal incidence power density was about $120 \mathrm{~W} / \mathrm{mm}^{2}$ at the crystal position, and the total power was about $38 \mathrm{~W}$. A set of $85^{\circ}$ inclination crystals was used. At a Bragg angle of $23.3^{\circ},(\mathrm{Si}(111), 5 \mathrm{keV})$, no thermal distortions were observed. At such an angle, the beam spreads across the surface of the crystal by a factor of 29 , thus the surface power density was about 4.1 $\mathrm{W} / \mathrm{mm}^{2}$.

Our most recent high-heat-load experiment was done at CHESS in September 1993, again using the CHESS/ANL undulator. One of the results is shown in Fig. VI.2. In this setup, the normal incidence power density on the crystal at $100 \mathrm{~mA}$ was $23 \mathrm{~W} / \mathrm{mm}^{2}$. (We are further from the source as compared to the previous run.) In this case, using another slotted crystal of about the same dimensions as before, in the flat geometry, we see that the $10 \%$ loss in intensity occurs at about $50 \mathrm{~mA}$ ring current, which, at this Bragg angle, corresponds to about $4.5 \mathrm{~W} / \mathrm{mm}^{2}$. 
These three independent experiments suggest to us that, by using the slottedcrystal geometry and liquid gallium as a coolant, we can handle about 4 $\mathrm{W} / \mathrm{mm}^{2}$ surface power density on the crystal. Keep in mind, however, that the total power involved in these tests was only about 300 to 400 watts at CHESS and only about 40 watts on X-25 at NSLS. At closed gap of the APS Undulator $A$ at $30 \mathrm{~m}$, the central cone contains about 750 watts, and the total power of the wiggler is about $7 \mathrm{~kW}$. Nevertheless, we see that our experimental numbers agree quite well with the FEA results. Fig. IV.5 shows that, for the APS wiggler beam, a surface power density of about 4 $\mathrm{W} / \mathrm{mm}^{2}$ would result in about a $5-\mu \mathrm{rad}$ thermal distortion on the crystal. This is consistent with our measurements. Currently, we are not able to detect distortions less than about $5 \mu$ rad due to the residual strains in our crystals from the fabrication and/or mounting process. 


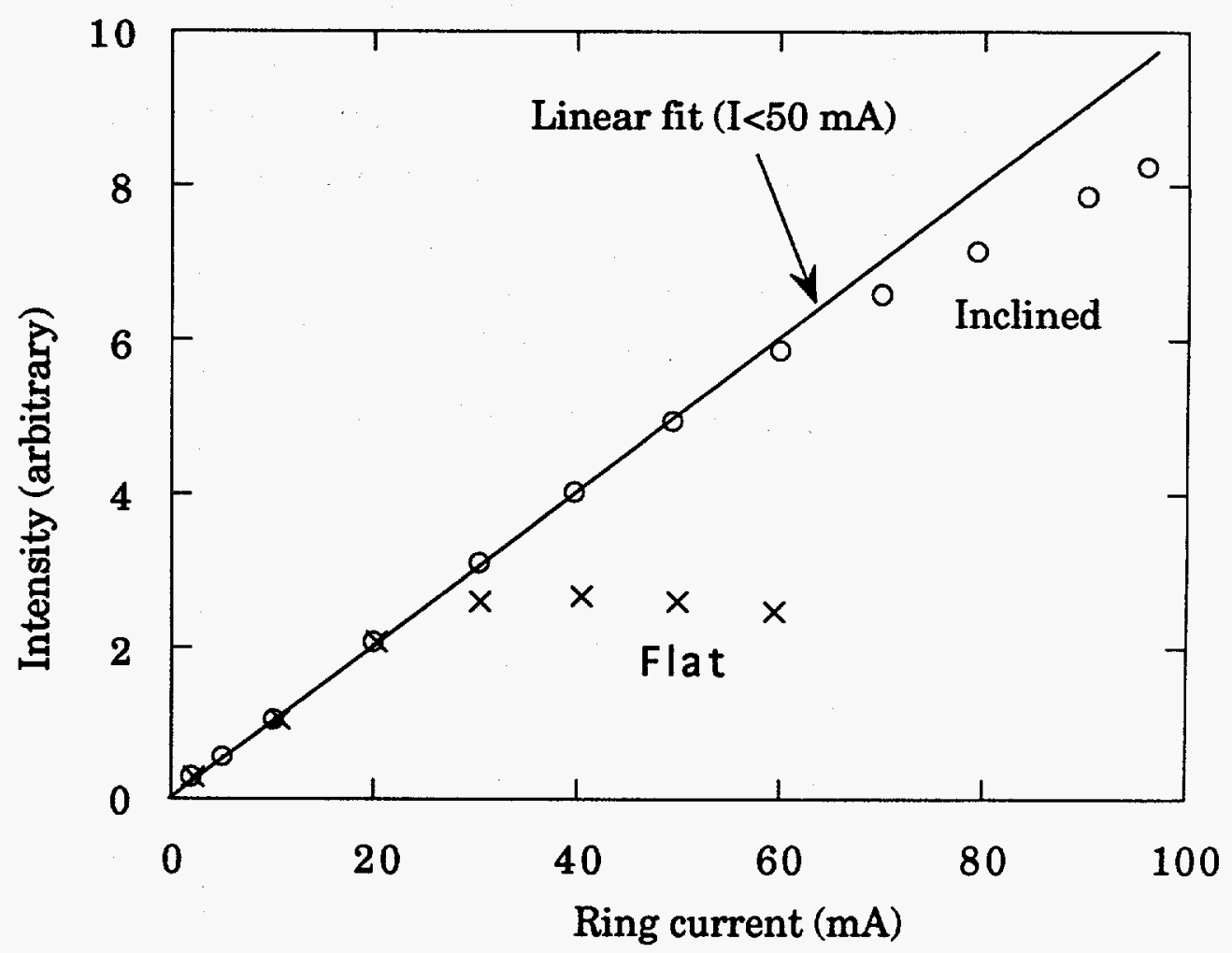

Fig. VI.1: Plot of intensity versus CESR current for a flat and an inclined crystal. The crystal had slots with liquid gallium as coolant. Data taken in June 1991 on CHESS/ANL undulator. The inclined crystal data were taken by rotating the flat crystal $70.5^{\circ}$ and using the $(1,1,-1)$ reflection. A straight line fit to the inclined crystal data for $\mathrm{I}<50 \mathrm{~mA}$ is shown for reference. The advantage of the inclined crystal is clear. The $10 \%$ intensity loss occurs at about $30 \mathrm{~mA}$ for the flat crystal and about $70 \mathrm{~mA}$ for the inclined crystal. 


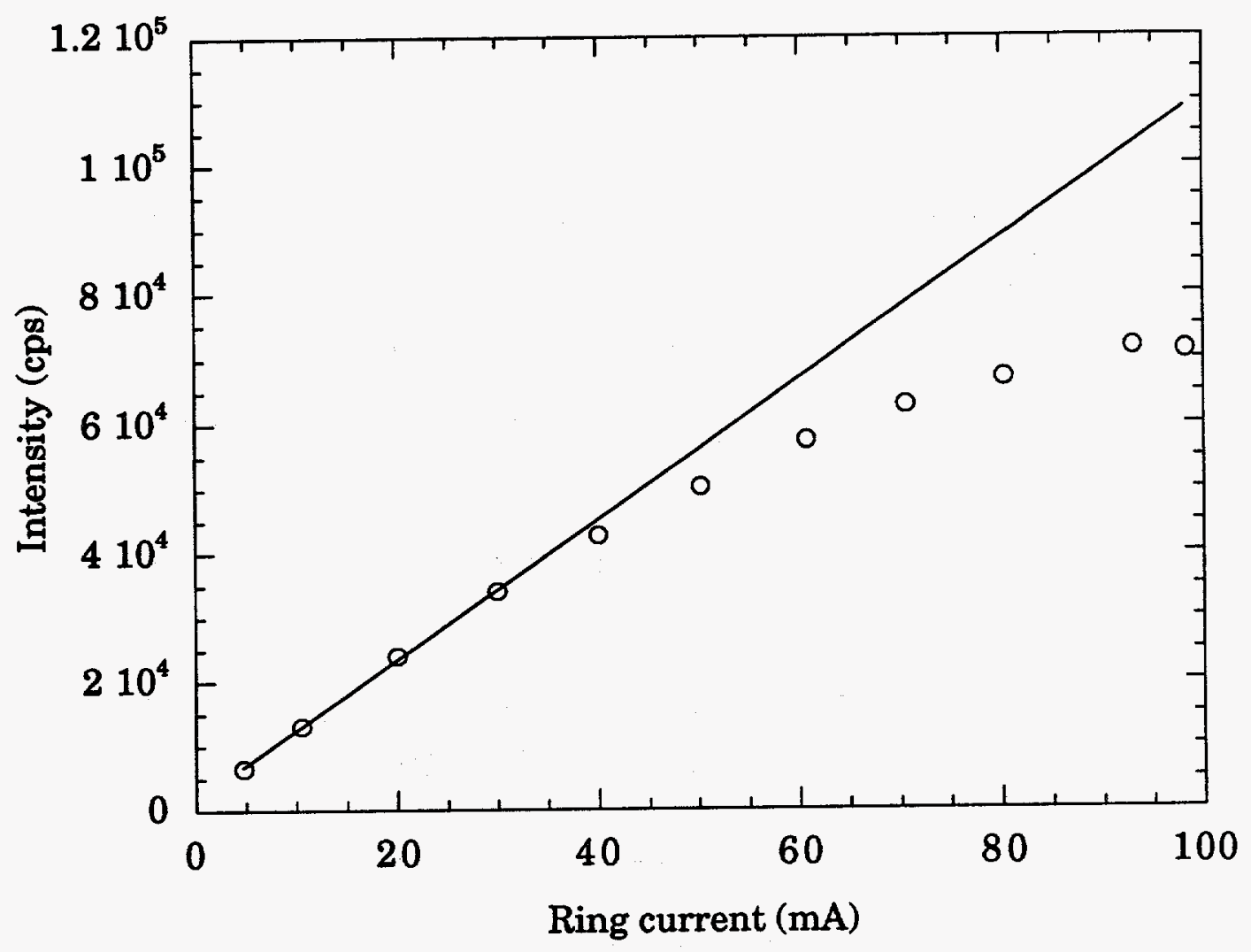

Fig. VI.2: Plot of intensity versus CESR ring current for a flat, slotted, and liquid-gallium-cooled crystal. Data taken in September 1993 on the CHESS/ANL undulator. The straight line is a linear fit to the $I \leq 30 \mathrm{~mA}$ data. The $10 \%$ intensity loss occurs at about $50 \mathrm{~mA}$. 


\section{Acknowledgment}

The authors would like to thank, A.M. Khounsary, R.K. Smither, and Z. Wang for their valuable comments, and Susan Picologlou for editing this document. This work is supported by the department of Energy, BESMaterials Sciences, under Contract No. W-31-109-ENG-38.

\section{References}

1. R.K. Smither, G.A. Forster, C.A. Kot and T.M. Kuzay, Nucl. Instrum. and Meth. A266 (1988) 517.

2. R.K. Smither, G.A. Forster, D.H. Bilderbak, M. Bedzyk, K. Finkelstein, C. Henderson, J. White, L.E. Berman, P. Stefan and T. Oversluizen, Rev. Sci. Instrum. 60 (1989) 1486.

3. R.K. Smither, W.K. Lee, A. Macrander, D. Mills, and S. Rogers, Rev. Sci. Instrum. 63 (1992) 1746.

4. C.S. Rogers, D. Mills, L. Assoufid, "The Cryogenic Cooling Program at the Advanced Photon Source," ANL/APS/TB-18 (1994).

5. C.S. Rogers and L. Assoufid (to be published in Rev. Sci. Instrum.).

6. W. K. Lee and D. Mills, "High Heat Load Monochromator Specifications," ANL/APS/TB-4 (1993).

7. A.M. Khounsary, Rev. Sci. Instrum. 63 (1992) 461.

8. A. T. Macrander, W. K. Lee, R. K. Smither, D. M. Mills, C. S. Rogers, and A. M. Khounsary, Nucl. Instrum. and Meth. A319 (1992) 188.

9. W. K. Lee. A. T. Macrander, D. M. Mills, C. S. Rogers and R. K. Smither, Nucl. Instrum. and Meth. A320 (1992) 381.

10. A. T. Macrander and W. K. Lee Nucl. Instrum. and Meth. A319 (1992) 155.

11. W. K. Lee and A. T. Macrander, Nucl. Instrum. and Meth. A319 (1992) 158. 
12. A. M. Macrander, A. M. Khounsary, and Graham, SPIE, Vol. 1739, High Heat Flux Engineering (1992) 502.

13. R.K. Smither and P.B. Fernandez, "Asymmetric-cut monochromator with adjustable asymmetry," to be published in Nucl. Instrum. and Meth.

14. A.K. Khounsary, R.K. Smither, and S. Davey, "Diamond Monochromator for High Heat Flux X-ray Beams," SPIE, Vol. 1739, High Heat Flux Engineering (1993) 628.

15. L. Assoufid and D. Mills, "Finite Element Analysis of a Diamond Crystal Subjected to the APS Undulator A Beam," Thermal Management of X-ray Optical Components for Synchrotron Radiation Workshop at Argonne National Laboratory, as part of The International Conference on Synchrotron Radiation Instrumentation, Stony Brook NY, USA (1994).

16. ANSYS-A general purpose finite element analysis program, Rev. 5.0a, Swanson Analysis System, Inc., Houston, PA 15342.

17. R. Lyon, "Forced convection heat transfer theory and experiments with liquid metals," USAEC report ORNL-361, Oak Ridge National Laboratory (1949).

18. V. Gnielinski, Int. Chem. Eng., 16 (1976) 359.

19. B.S. Petukhov, Heat Transfer, ed., T.F. Irvine and J.P. Hartnett, Vol. 6, pp. 503-564, Academic Press, NY, 1970.

20. Thermophysical Properties of Matter, Vol. 2 Thermal Conductivity Y.S. Toukoulian, R.W. Powell, C.Y. Ho, P.G. Klemens, eds., IFI/Plenum, 1970, and Vol. 13, Thermal Expansion, Y.S. Toukoulian, R.K. Kirby, R.E. Taylor, and T.Y. Lee, eds., IFI/Plenum, 1979

21. G.K. Shenoy, P.J. Viccaro, and D. Mills, "Characteristics of the 7-GeV Advanced Photon Source: A Guide for Users," Argonne National Laboratory, ANL-88-9 (1988).

22. T. Oversluizen, T. Matsushita, T. Ishikawa, P.M. Stefan, S. Sharma, A. Mikuni, Rev. Sci. Instrum. 60 (7), (1989) 1493. 
23. R. J. Dejus, A.M. Khounsary, D.A. Brown and P.J. Viccaro, "Calculation of wiggler spectrum and its absorption in media," Nucl. Instrum. and Methods in Phys. Res., Sect. A319 (1992) 207.

24. T. W. Tonnessen and J. Arthur, SPIE, Vol. 1739, High Heat Flux Engineering (1992) 622.

25. J. Arthur, W.H. Tompkins, C. Troxel, R.J. Contolini, E. Schmitt, D.H. Bilderbak, C. Henderson, J.White, and T.Settesten, "Microchannel water cooling of Silicon x-ray monochromator crystals," Rev. Sci. Instrum., 63 (1) (1991) 433.

26. R.A. Riddle, SPIE, Vol. 1997, High Heat Flux Engineering II (1993) 83.

27. T.M. Kuzay, J. T. Collins, A. Khounsary, and J. Viccaro, "Experimental and Analytical Studies on Fixed Mask Assembly for APS with Enhanced Cooling," Advanced X-ray/EUV Radiation Sources and Applications, SPIE Vol. 1345 (1990) 55.

28. B. Lai, A. Khounsary, R. Savoy, L. Moog, and E Gluskin, "Wiggler A Characteristics and Specification," ANL/APS/TB-11 (1993).

29. F. Cerrina, B. Lai, K. Chapman, C. Welnak, and P. Runkle, Center of XRay Lithography, University of Wisconson.

30. W. Yun, A.M. Khounsary, B. Lai, and E. Gluskin, "Use of a Mirror as the First Optical Component For Undulator Beamline at the APS," ANL/APS/TB2 (1992).

31. R.J. Dejus, B. Lai, E.R. Moog, and E. Gluskin, "Undulator A Characteristics and Specification: Enhanced Capabilities," ANL/APS/TB-17 (1994).

32. R.P. Walker and B. Diviacco, "URGENT-A computer program for calculating undulator radiation spectral, angular, polarization, and power density properties," Rev. Sci. Instrum. 63 (1) (1992) 392. 
33. A.T. Macrander, W.K. Lee, R.K. Smither, D.M. Mills, C.S. Rogers and A.M. Khounsary, "High heat load performance of an inclined-crystal monochromator with liquid gallium cooling on the CHESS-ANL undulator," Nucl. Instrum. and Meth. A 319 (1992) 188.

34. W.K. Lee, A.T. Macrander, D.M. Mills, C.S. Rogers and R.K. Smither, and L.E. Berman, "Performance of gallium-cooled $85^{\circ}$ inclined silicon momochromator for high power density X-ray beam," Nucl. Instrum. and Meth. A320 (1992) 381. 